
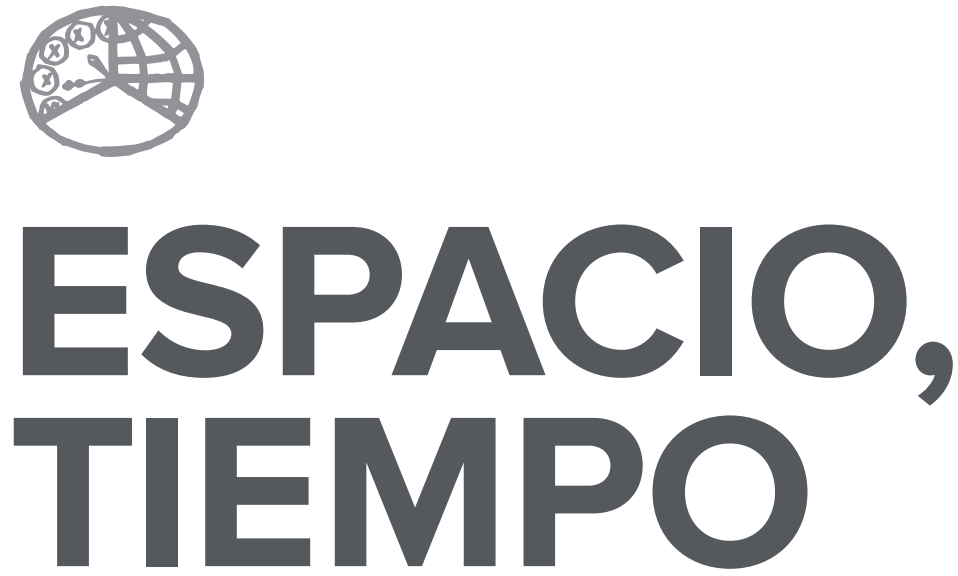

AÑO 2016

ISSN 0214-9745

E-ISSN 2340-1362
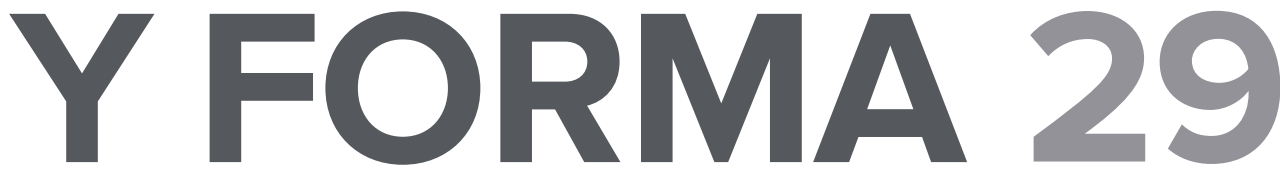

SERIE III HISTORIA MEDIEVAL

REVISTA DE LA FACULTAD DE GEOGRAFÍA E HISTORIA 


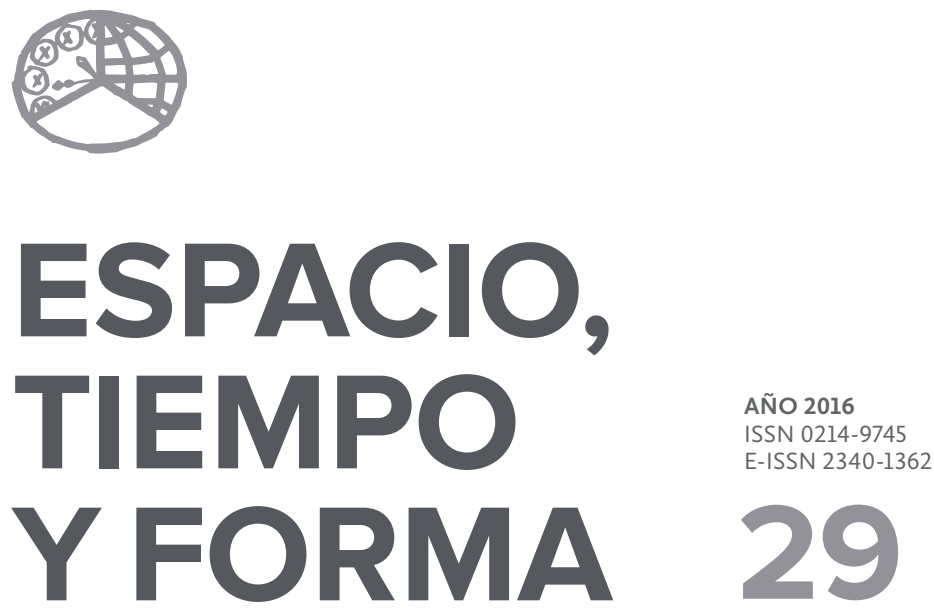

SERIE III HISTORIA MEDIEVAL

REVISTA DE LA FACULTAD DE GEOGRAFÍA E HISTORIA

http://dx.doi.org/10.5944/etfiii.29.2016

\section{UกED}

UNIVERSIDAD NACIONAL DE EDUCACIÓN A DISTANCIA 
La revista Espacio, Tiempo y Forma (siglas recomendadas: ETF),

de la Facultad de Geografía e Historia de la UNED, que inició su publicación el año 1988, está organizada de la siguiente forma:

$$
\begin{aligned}
& \text { SERIE I - Prehistoria y Arqueología } \\
& \text { SERIE II - Historia Antigua } \\
& \text { SERIE III - Historia Medieval } \\
& \text { SERIE IV - Historia Moderna } \\
& \text { SERIE V - Historia Contemporánea } \\
& \text { SERIE VI - Geografía } \\
& \text { SERIE VII - Historia del Arte }
\end{aligned}
$$

Excepcionalmente, algunos volúmenes del año 1988 atienden a la siguiente numeración:
N. ${ }^{\circ} 1$ - Historia Contemporánea
N. ${ }^{\circ} 2-$ Historia del Arte
N. ${ }^{\circ} 3-$ Geografía
N. ${ }^{\circ} 4 \quad-$ Historia Moderna

ETF no se solidariza necesariamente con las opiniones expresadas por los autores.

UNIVERSIDAD NACIONAL DE EDUCACIÓN A DISTANCIA

Madrid, 2016

SERIE III - HISTORIA MEDIEVAL N. ${ }^{\circ} 29,2016$

ISSN 0214-9745 · E-ISSN 2340-1362

DEPÓSITO LEGAL M-21037-1988

URL: ETF III - HISTORIA MEDIEVAL · http://revistas.uned.es/index.php/ETFIII

DISEÑO Y COMPOSICIÓN

Carmen Chincoa Gallardo · http://www.laurisilva.net/cch

Impreso en España · Printed in Spain 


\section{ARTÍCULOS}





\title{
LOS DUEÑOS DEL DINERO. \\ PRESTAMISTAS ABULENSES \\ A MEDIADOS DEL SIGLO XV
}

\section{THE MASTERS OF MONEY. MONEY-LENDERS IN MID-FIFTEENTH-CENTURY ÁVILA}

\author{
Octavio Colombo \\ Recepción: 2015/2/21 C Comunicación de observaciones de evaluadores: 2015/10/23 . \\ Aceptación: 2015/10/28 \\ DOI: http://dx.doi.org/10.5944/etfiii.29.2016.14102
}

\section{Resumen}

El objetivo del presente trabajo es reconstruir el perfil socioeconómico de los prestamistas abulenses que aparecen en el libro del notario Gómez González entre los años I448 a I45I. Allí consta la existencia de unas setecientas operaciones de préstamo, de las cuales más de la mitad tienen como acreedores a un pequeño número de sujetos. A su vez, los mismos aparecen involucrados en numerosas actividades económicas adicionales. Se realiza en primer lugar una presentación del conjunto de las deudas consignadas, su distribución temporal, sus montos y de las características globales de prestamistas y prestatarios. Luego, se analizan las actividades de los acreedores más prominentes, utilizando para ello documentación complementaria del concejo de Ávila. En base a ello, por último, se intenta una reconstrucción del perfil social de este segmento de la sociedad concejil bajomedieval.

\section{Palabras clave}

Elites; prestamistas; crédito; Ávila.

\section{Abstract}

The objective of this paper is to reconstruct the socio-economic profile of money-lenders in Ávila which appear in the books of the public notary, Gómez González, between I448 and I45I. From this source, it is possible to identify close

1. Universidad de Buenos Aires. Consejo Nacional de Investigaciones Científicas y Técnicas (Argentina). C.e.: octacolombo@hotmail.com 
to seven hundred credit records, of which more than half belong to a small group of lenders. Furthermore, these creditors also appear taking part in many additional economic activities. First, we present a comprehensive examination of these loans, their chronological distribution, the monetary quantities and the general features of the lenders and the borrowers. Secondly, we analyze the activities of the most prominent lenders using supplementary documents from Ávila. Finally and based on this collected data, we intend to reconstruct the social profile of this group within late-medieval urban society.

Keywords

Elites; Money-Lenders; Credit; Ávila. 


\section{INTRODUCCIÓN}

El problema del préstamo dinerario tiene una larga tradición en la historiografía medieval ${ }^{2}$. En la actualidad, la cuestión reaparece con vigor ligada especialmente a dos tópicos. Por un lado, el estudio de la circulación y los mercados, que ha conocido un sorprendente desarrollo en las últimas dos décadas 3 . La percepción historiográfica respecto del dinamismo de las economías campesinas sujetas al dominio feudal ha llevado a destacar la mercantilización y monetización de las relaciones agrarias, brindando nueva información sobre el desarrollo del crédito en el ámbito rural ${ }^{4}$. Por otro lado, las recientes investigaciones sobre las elites del común, un campo de investigaciones que incluye una variedad de aspectos vinculados $^{5}$. Los especialistas señalan que, entre la variedad de fuentes de ingreso que

2. Sólo a título ilustrativo, mencionemos a LE GoFf, Jacques, La bolsa y la vida. Economía y religión en la Edad Media, Barcelona, Gedisa, 1987. LITTLE, Lester, Pobreza voluntaria y economía de beneficio en la Europa medieval, Madrid, Taurus, 1980. NeLSON, Benjamin, The Idea of Usury. From Tribal Brotherhood to Universal Otherhood, Chicago, University of Chicago Press, 1969. Entre los hispanistas, además de las referencias que se hacen más adelante, destacan entre otros: GARCíA DE VALDEAVELLANO, Luis, «El «Renovo»: notas y documentos sobre los préstamos usurarios en el reino astur-leonés (siglos X-XI)», Cuadernos de Historia de España, $57-58$ (1973), pp. 408-448. Benito RuAno, Eloy, «Usura y «cambios» en el León medieval», Archivos Leoneses, $47-48$ (1970), pp. 203-208. CLAVERo, Bartolomé, Usura: del uso económico de la religión en la historia, Madrid, Tecnos, 1984. Idem, «Interesse: traducción e incidencia de un concepto en la Castilla del siglo XVI», Anuario de historia del derecho español, 49 (1979) pp. 39-98. Borrero FernándeZ, M. de las Mercedes, «Efectos del cambio económico en el ámbito rural. Los sistemas de crédito en el campo sevillano (fines del siglo XV y principios del XVI)», En la España medieval, 8 (1986), pp. 219-244. PADrós, Joan, «Endeudamiento y límites de la solidaridad campesina en la Cataluña del siglo XVI», Historia Agraria, 20 (2000), pp. 41-60. FurIó, Antoni, «Endettement paysan et crédit dans la Péninsule Ibérique au Bas Moyen Âge», en BerTHE, Maurice (ed.), Endettement paysan et crédit rural dans l'Europe médiévale et moderne, Toulouse, Presses Universitaires du Mirail, 1998, pp. 139-167.

3. En especial por el impulso de la historiografía anglosajona. Algunos referentes relevantes son BRITNELL, Richard, The Commercialization of English Society, 1000-1500, Manchester, Manchester University Press, 1996. Idem y CAMPBelL, Bruce (eds.), A Commercialising Economy. England 1086 to c. 1300, Manchester, Manchester University Press, 1995. MassChaele, James, Peasants, Merchants and Markets. Inland Trade in Medieval England, 1150-1350, New York, St. Martin's Press, 1997. Kowaleski, Maryanne, Local Markets and Regional Trade in Medieval Exeter, Cambridge, Cambridge University Press, 2002. Una excelente presentación crítica en HATCHER, John, y BAILEY, Mark, Modelling the Middle Ages. The History and Theory of England's Economic Development, Oxford, Oxford University Press, 2001, pp. 121 ss.

4. Briggs, Chris, Credit and Village Society in Fourteenth Century England, Oxford, Oxford University Press, 2009.

5. Sin pretender exhaustividad, son de referencia obligada los trabajos de las jornadas de Flaran reunidos en Menant, François, y Jessenne, Jean- Pierre (eds.), Les Élites rurales dans l'Europe médiévale et moderne, Toulouse, Presses Universitaires du Mirail, 2007. Véase también el dossier de Mélanges de l'École française de Rome. Moyen Âge, $n^{\circ}$ 124/2 (2012), que destaca por las referencias al mundo bizantino y musulmán. Entre los hispanistas fue pionero el trabajo de AsENJo GonZÁLEZ, María, «Labradores ricos: nacimiento de una oligarquía rural en la Segovia del siglo XV», En la España medieval, 4 (1984), pp. 63-86. También había realizado menciones al tema para el siglo XVI SALOMON, Noël, La vida rural castellana en tiempos de Felipe II, Barcelona, Ariel, 1982, p. 280. APARISI ROMERO, Fredric, «Las élites rurales en la Edad Media como objeto de estudio: de la marginalidad al centro del debate historiográfico», Historia. Instituciones. Documentos, 40 (2013), pp. 11-34. FURIó, Antoni, «Las élites rurales en la Europa medieval y moderna. Una aproximación de conjunto», en Rodríguez, Ana (ed.), El lugar del campesino. En torno a la obra de Reyna Pastor, Valencia, PUV, 2007, pp. 391-421. AstARITA, Carlos, «Procuradores pecheros», en Idem, Del Feudalismo al capitalismo. Cambio social y político en Castilla y Europa Occidental, 1250-1520, Valencia, PUV, 2005, pp. 113-144. CLemENTE RAMOS, Julián, «Élites rurales en Extremadura a finales de la Edad Media: el mayoral Juan Rubio (+1499)», Studia Historica. Historia Medieval, 29 (2011), pp. 229-246. Sobre las élites urbanas del común véase DEL VAL VALDIVIESO, M. Isabel, «Indicios de la existencia de una clase en formación: el ejemplo de Medina del Campo a fines del siglo XV», Anales de la Universidad de Alicante. Historia Medieval, 7 (1988-1989), pp. 193-224. Idem, «Ascenso social y lucha por el poder en las ciudades castellanas del siglo XV», En la España Medieval, 17 (1994), pp. 157-184. Guerrero NavArrete, Yolanda, «Élites urbanas en el siglo XV: Burgos y Cuenca», Revista d' Historia Medieval, 9 (1998), pp. 81-104. Una propuesta analítica global en JARA FuENTE, José Antonio, «Élites urbanas y sistemas concejiles: Una propuesta teórico-metodológica para el análisis de los subsistemas de poder en los concejos castellanos de la Baja Edad Media», Hispania, 207 (2001), pp. 221-266. Para un estudio de caso de origen 
caracteriza a estos sectores emergentes, su rol como prestamistas suele ocupar un papel relevante ${ }^{6}$. Esta perspectiva, en especial, constituye la fuente de inspiración del presente trabajo, donde se intenta reconstruir el perfil socio-económico de algunos prestamistas abulenses de mediados del siglo XV.

Esa coyuntura histórica requiere un breve comentario. En efecto, las abundantes y reiteradas menciones a la usura que aparecen en las Cortes desde mediados del siglo XIII y hasta principios del XV, han llevado a tratar de forma privilegiada este período, en el que además destaca el aspecto confesional del conflicto ${ }^{7}$. Por contraste, desde el ordenamiento de 1405 hasta la normativa de los Reyes Católicos en el último cuarto de ese siglo, las Cortes castellanas son llamativamente parcas en sus disposiciones sobre el préstamo. Veamos algunos ejemplos. En I435 se condena una forma habitual de encubrimiento de la usura, practicada por los cristianos, consistente en la realización de una venta ficticia, al mismo tiempo que se solicita que los prestamistas puedan dar en çierta manera rrazonable por los menesteres delos pueblos ${ }^{8}$. Muchas referencias que aparecen a las deudas en las Cortes del siglo XV tienen este sentido de protección a los acreedores: se menciona el alargamiento malicioso de los pagos por parte de los deudores para eludir sus obligaciones y el perjuicio que las esperas provocan a los prestamistas ${ }^{9}$, la necesidad de aportar bienes que sirvan como garantía para el cobro de las deudas ${ }^{\mathrm{IO}}$, el peligro de presumir el carácter usurario de los contratos lícitos ${ }^{\mathrm{II}}$, y que los moros y judíos, al igual que los cristianos, puedan ser encarcelados por sus deudas ${ }^{12}$. Un documento posterior dirigido al corregidor de Ávila relativo a un proceso contra prestamistas judíos incluso aclara que debía entenderse que hasta I480 la «usura» era legal, aunque el alcance de la afirmación no es en absoluto claro ${ }^{\mathrm{I3}}$.

\footnotetext{
artesanal, LLIBRER ESCRIG, Josep, «Artesanos emprendedores en la industria textil. Del taller al mercado: El caso del pelaire contestano Bernat Martí (1469-1482)», En la España medieval, 37 (2014), pp. 295-317.

6. Bourin, Monique, «Peasant Elites and Village Communities in the South of France, 1200-1350», Past and Present, 195 Suppl. 2 (2007), pp. 101-114.

7. Crespo Álvarez, Macarena, «Judíos, préstamos y usuras en la Castilla medieval. De Alfonso X a Enrique IIl», Edad Media. Revista de Historia, 5 (2002), pp. 179-215. CASTÁN LANASPA, Guillermo, «Créditos, deudas y pagos en el área rural castellano-leonesa (siglos XI-XIV)», Studia Historica. Hist. Medieval, I (1983), pp. 67-86. Monsalvo Antón, José María, Teoría y evolución de un conflicto social. El antisemitismo en la Corona de Castilla en la Baja Edad Media, Siglo XXI, Madrid, 1985. Colombo, Octavio, «La negociación en torno a la usura en Castilla, 1258-1405. Economía, poder y religión en la Baja Edad Media», Anales de Historia Medieval, Universidad de Alicante, 14 (2003-2006), pp. 85-110. En cambio, para el siglo XV la situación de los judíos ha sido extensamente tratada en los trabajos de CANTERA MonTENEGRO, Enrique, «La legislación general acerca de los judíos en el reinado de Juan II de Castilla», Espacio, Tiempo y Forma. Serie III. Historia Medieval, 25 (2012), pp. 119-146. Idem, «Algunas notas sobre Abraham Bienveniste, Rab Mayor de los judíos y tesorero real en tiempos de Juan II de Castilla», Espacio, Tiempo y Forma. Serie III. Historia Medieval, 27 (2014), pp. 161-191. Idem, «Una familia de prestamistas y arrendadores judíos en tiempos de la expulsión: Los Soto de Aranda del Duero», Espacio, Tiempo y Forma. Serie III. Historia Medieval, 12 (1999), pp. 11-46. Véase también CASTAÑo GonzÁLEZ, Javier, «Las aljamas judías de Castilla a mediados del siglo XV: la Carta Real de 1450», En la España medieval, 18 (1995), pp. 181-203.

8. Cortes de los Antiguos Reinos de León y de Castilla, Real Academia de la Historia, Madrid, Tomos III-IV, 1866-1882 (en adelante: Cortes); tomo III, 1435, pet. 35, p. 234.

9. Cortes, III, 1433, pet. 18; 1473, pet. 30; Cortes, IV, 1480, pet. 46.

10. Cortes, IV, 1480, pet. 50; 1505 , pet. 64.

11. Cortes, III, 1462, pet. 23; Cortes, IV, 1476, pet. 36 ; 1512, pet. 6 .

12. Cortes, IV, 1476, pet. 11.

13. ... de qualesquier usuras que dizen averles levado antes del año que pasó de LXXX años en que nos en la Cortes de
} 
Algunas menciones documentales parecen incluso indicar una clara conciencia respecto de la necesidad del préstamo para una economía agraria sujeta a extracciones periódicas de dinero por parte del poder feudal. En I477, por ejemplo, los pueblos de la Tierra de Ávila afirmaban que desde antiguo an estado en costunbre de demandar maravedís prestados a algunas personas de la dicha çibdad ansý cristianos commo judíos e moros por algún ynterese para con ello afrontar el pago de las dichas sumas e quantías de maravedís que asý se reparten a los pecheros ${ }^{14}$. Tal vez éste no sea un indicio menor respecto de la tolerancia de hecho frente a la diversidad de formas de endeudamiento que registra la documentación, las cuales por norma se limitan a respetar el requisito formal de no consignar la existencia de logro alguno en los contratos ${ }^{15}$.

Es en este contexto en el que se ubica nuestra investigación. Partimos entonces del estudio de las relaciones de préstamo registradas en el libro del notario abulense Gómez González para los años I448-I45I. Luego procedemos a la identificación de las actividades y el perfil social de los prestamistas más importantes utilizando también el conjunto de la documentación concejil disponible.

\section{LOS PRÉSTAMOS}

El registro contiene el resumen de todas las operaciones realizadas ante el mencionado escribano entre fines de enero de 1448 y mediados de marzo de $\mathrm{I} 45 \mathrm{I}^{16}$. Allí encontramos 705 referencias a préstamos en dinero o en producto, lo

Toledo, el dicho año, fezymos la ley en que defendimos que se levasen las dichas usuras, no prendáys ni prendéys ni enbargéys a los dichos, Martín Rodríguez, José Luis, Documentación medieval abulense en el Registro General del Sello, vol. VII (4-I-1492 a 24-XII-1492), Ávila, Institución Gran Duque de Alba, 1996, doc. 33, 26/6/1492, p. 98. No es claro, sin embargo, si «usura» refiere aquí a un interés moderado o a cualquier tipo de interés.

14. Martín Rodríguez, José Luis, Documentación medieval abulense en el Registro General del Sello, vol. I (30-X1467 a 18-IX-1479), Ávila, Institución Gran Duque de Alba, 1995 (en adelante: RGS, vol. I), doc. 52, 9-3-1477, p. 128. Otra referencia significativa similar en Sobrino CHOmón, Tomás, Documentación del Archivo Municipal de Ávila. Vol. II (1436-1477), Ávila, Institución Gran Duque de Alba, 1999 (en adelante: Documentación de Ávila II), doc. 176, 4/4/1476, p. 172. Es incluso muy significativo que, en un pleito entre la ciudad y la aljama de los judíos, el procurador de esta última ensaye una justificación conceptual del interés: que habían de ser remunerados por casa de sus enpréstidos no por vía de logro ni de usura salvo por vía de interese, RGS, vol. I, doc. 93, 18-9-1479, p. 246.

15. Aguilera BarChet, Bruno, «El préstamo en Extremadura a mediados del siglo XVI: notas para el estudio del derecho privado de la Corona de Castilla en la Edad Moderna», Anuario de la Facultad de Derecho, 11 (1993), p. 312 ss. El encubrimiento del interés bastaba en general para garantizar la legalidad del contrato, lo que explica la proliferación de los registros al respecto. En este sentido, es incluso notable que la figura del crédito se utilizara para encubrir otras operaciones: por ejemplo, en 1486 los arrendadores de la alcabala de los paños de Ávila y su Tierra se quejan porque las ventas fiadas se anotan como préstamos de dinero a fin de no pagar ese impuesto: aunque son por razón de conpras de paños diz que dizen los dichos contrabtos que son de maravedís de enpréstito o de otras cosas a fyn de non pagar el alcavala dello, Del Ser QuIJANo, Gregorio, Documentación medieval abulense en el Registro General del Sello, vol. IV (31-VIII-1485 a 3-V-1488), Ávila, Institución Gran Duque de Alba, 1995, doc. 29, 13-3-1486, pp. 68-9.

16. Jiménez Hernández, Sonsoles y Redondo Pérez, Asunción, Catálogo de Protocolos Notariales del Archivo Histórico Provincial de Ávila (Siglo XV), dos tomos, Ávila, Institución Gran Duque de Alba, 1992 (en adelante: Catálogo). Las operaciones que incluyen a miembros de la comunidad judía también fueron reseñadas de modo escueto en LEÓN TelLo, Pilar, Judíos de Ávila, Ávila, Instituto «Gran Duque de Alba», 1963, pp. 132-136. También utilizó esta documentación entre otros García Garcimartín, Hugo, Articulación jurisdiccional y dinámica socioeconómica de un espcio natural: la 
que constituye el $43 \%$ del total de las 1627 actuaciones notariales registradas ${ }^{17}$. La distribución mensual de estas obligaciones permite una primera aproximación al problema (véase el cuadro del Apéndice I). Lo más evidente es el incremento tendencial de la cantidad de deudas en el período, lo que indica que se trata de una coyuntura de crisis agraria ${ }^{18}$. En términos anuales, los II meses de 1448 contabilizan un total de Ior préstamos (promedio mensual 9,2), mientras que en I449 tenemos I9I préstamos (promedio mensual 15,9) y en I450 encontramos 327 registros (promedio mensual 27,3). Para I45I sólo contamos con información completa de los meses de enero y febrero, que no son los meses de mayor registro de préstamos de cada año, donde se contabilizan 28 y 32 deudas respectivamente (promedio 30). Dicho de otro modo, entre I448 y I450 el promedio de deudas mensuales se triplica y la tendencia marcada por el inicio de I45I vislumbra un incremento probable a futuro aún mayor.

Sin embargo, esto no quiere decir que la única función del endeudamiento fuera la obtención de bienes de consumo en una coyuntura de carestía. La distribución mensual de los préstamos no presenta una correspondencia lineal con el ciclo agrario. Esto obedece a que el endeudamiento de los pecheros también tiene la función de garantizar el cumplimiento del pago de rentas que se recaudan principalmente en dinero, lo que aparece explícitamente mencionado en innumerables documentos del área que hemos analizado en otro lugar ${ }^{19}$. Este aspecto resulta manifiesto si se discriminan las deudas en dinero y las deudas en granos (véase el cuadro del Apéndice 2). Estas últimas presentan una altísima correspondencia con el ciclo agrario: tras un aumento sostenido que culmina inmediatamente antes de la cosecha en el pico del segundo trimestre, se registra

\footnotetext{
cuenca del Alberche (siglos XII-XV), Tesis Doctoral, Universidad Complutense de Madrid, 2002. Por nuestro lado, hemos presentado los aspectos más generales de esta serie documental en Colombo, Octavio, «¿Por qué el campesino se endeuda? El significado de la usura medieval», Sociedades Precapitalistas. Revista de Historia Social, 5/1 (2015), pp. 1-20. Destacó la importancia de las fuentes notariales AsEnjo GonZÁLEZ, María, «Las ciudades medievales castellanas. Balance y perspectivas de su desarrollo historiográfico (1990-2004)», En la España medieval, 28 (2005), p. 420. Recuérdese que los escribanos debían asentar en un libro un breve resumen del contenido de los actos legales que pasaban ante ellos; Rojas VACA, María Dolores, «Los inicios del notariado público en el reino de Castilla. Aportación a su estudio», Anuario de Estudios Medievales, 31/1 (2001), pp. 343 ss.; Álvarez-CARBAjAL, Francisco, El registro del notario Martín Fernández de Ruiforco (1468). Un escribano público en el Condado de Luna, Sevilla, Sociedad Española de Técnicas Historiográficas, 2014, pp. 42-3. Véase también Rodríguez MATEOS, Joaquín, «Escribanos públicos en Huelva: los protocolos notariales y el Archivo Histórico Provincial», Huelva en su historia, 8 (2001), pp. 131-150; desde un punto de vista formal, BonO Y Huerta, José, «Conceptos fundamentales de la diplomática notarial», Historia. Instituciones. Documentos , 19 (1992), pp. 73-88. Para el caso de Ávila, CASAdo QuinTANILLA, Blas, «Nombramiento de escribanos públicos en Ávila, y sus circunstancias, en tiempos de los Reyes Católicos», Espacio, Tiempo y Forma, Serie III, Historia Medieval, 17 (2004), pp. 115-130. Idem, «Autenticidad documental y escribanos de Ávila en la Baja Edad Media», Espacio, Tiempo y Forma, Serie III, Historia Medieval, 1 (1988), pp. 175-192.

17. Por lo que resulta un registro inusualmente prolífico; compárese por ejemplo con la información de ÁLVAREZCARBAJAL, Ob. cit., pp. 30, 54; y Diez BedmaR, M. del Consuelo, «Los libros de protocolos notariales del Archivo Histórico Provincial de Jaén», Boletín del Instituto de Estudios Giennenses, 183 (2003), pp. 69-130; o con el recientemente publicado por SANz Fuentes, M. Josefa, Documentación medieval de la catedral de Ávila: Registro de Alfonso González de Bonilla (17VI-1465 a 5-VIII-1468), Ávila, Institución Gran Duque de Alba, 2014 (en adelante: Registro de Alfonso González de Bonilla).

18. SALRACH, Josep, El hambre en el mundo. Pasado y presente, Valencia, PUV, 2012, p. 136.

19. Colombo, «¿Por qué el campesino se endeuda?». Véase también CASADO Alonso, Hilario, Señores, mercaderes y campesinos. La comarca de Burgos a fines de la Edad Media, Valladolid, Junta de Castilla y León, 1987, p. 531.
} 
una caída abrupta en el tercer trimestre, momento a partir del cual se reinicia el ciclo ascendente. Por contraste, las deudas en dinero revelan un patrón mucho más distorsionado, donde el movimiento esperable dada la estacionalidad del ciclo productivo aparece modificado por la existencia de otros movimientos irregulares ascendentes en meses puntuales, lo que se corresponde con el carácter variable, tanto en lo que hace al momento de recaudación como a los montos implicados, de las imposiciones regias y concejiles.

Estos elementos llevan a pensar en la situación precaria de los deudores, lo que también se comprueba por otros indicios. Uno de ellos es el monto mayoritariamente pequeño de las deudas en dinero (véase el cuadro del Apéndice 3). Sobre un total de 555 préstamos en maravedíes consignados en el registro, tres cuartas partes (4I5 préstamos) son por montos menores a 500 maravedíes; más aún, dos terceras partes (359 préstamos) son por montos menores a 300 maravedíes.

Como parámetro de comparación para dimensionar el significado de estas magnitudes, pueden ponerse en relación con algunas imposiciones recaudadas en los mismos años. En el registro del notario que analizamos aparecen diversas menciones a la recolección de doce monedas para los años I448, I449 y I450 ${ }^{20}$. Puesto que cada «moneda» equivale a 8 maravedíes, esto supone una imposición anual de 96 maravedíes por pechero, a partir de cuantías mínimas insignificantes $^{21}$. A modo ilustrativo puede citarse el caso de Diego Martín, hijo de Pascual Sánchez, vecino de Bermudo, quien en agosto de I450 se compromete a pagar I92 maravedíes que adeuda del pecho de las doce monedas suyo y de su madre, debiendo diez días más tarde solicitar un préstamo de roo maravedíes, dinero probablemente utilizado con ese $\mathrm{fin}^{22}$. A la recaudación en concepto de monedas, además, deben sumarse otras imposiciones regias directas, como el pedido ${ }^{23}$; a lo

20. Luis González del San Juan, personaje del que hablaremos más abajo, otorga poder a otro para recaudar las doce monedas del concejo de Horcajuelo (Catálogo, doc. 249, 18-9-1448) y del concejo de Santa María de Robledo (doc. 269, 27-9-1448). Pecheros insolventes se obligan a pagar diversas cuantías que quedaron debiendo de dicho tributo en docs. 294 y 295, 8-10-1448; 296, 9-10-1448; 316, 25-10-1448; 665, 2-9-1449; 690, 16-9-1449; 1205 a 1207, 6-8-1450; 1216 a 1219, 10-8-1450. Téngase en cuenta que no es una imposición fuera de lo habitual: en años inmediatos anteriores se habían recaudado 15 y hasta 20 monedas anuales, como sabemos por los compromisos de pago atrasado registrados en docs. $238,6-9-1448$ y $430,7-2-1449$.

21. Ladero Quesada informa de un reparto de ocho monedas en 1447 y otro de siete en 1451, con cuantías mínimas valuadas en 250 y 240 maravedíes respectivamente para el pago completo del tributo. Son magnitudes extremadamente bajas en relación a las que se utilizan para el reparto de los pedidos de Cortes: en 1432, por ejemplo, los procuradores denuncian que la cabeza mayor del pecho está valuada en 1.200 maravedíes, delo qual rrecresçe grand dapno alos pecheros pobres, por quanto tanto ha de pagar enel pecho elque tiene valia de mill e dozientos mrs. commo el que tiene valia de çinquenta mill mrs. o mas, Cortes, III, 1432, pet. 48, p. 153. Compárese con las quince monedas recaudadas el año siguiente (1433), en tres plazos de cinco, donde debían pagar todos los pecheros que tuvieran bienes por encima de 150 maravedíes; Ladero Quesada, Miguel Angel, La Hacienda Real de Castilla en el Siglo XV, Universidad de La Laguna, 1973, pp. 202-203.

22. Catálogo, docs. 1205 (6-8-1450) y 1233 (16-8-1450). Diego Martín ya había tenido que pedir prestadas 4 fanegas de centeno el año anterior (idem, doc. 630, 18-7-1449).

23. LADERO QUeSADA, Ob. cit., p. 207; el autor calcula que cada moneda recaudada equivalía a un millón y medio de maravedíes. Si se suman las 8 monedas de 1447 y las 12 de cada año entre 1448 y 1450, daría un total de 66 millones, pero Ladero Quesada calcula que la totalidad del «servicio» (monedas y pedidos) para esos cuatro años suma 120 millones (idem, cuadro inserto entre las páginas 218 y 219). Aun así el autor considera que en casi todos los años puntuales en que hay datos disponibles, la cuantía recaudada como pedido supera a las monedas (p. 201). Recuérdese 
que a su vez abría que agregar, por supuesto, alcabalas y tercias ${ }^{24}$, pechos concejiles, etc. Dada la variedad de tributos, criterios y formas de recaudación, y la falta de información al respecto, nos es imposible calcular siquiera de modo aproximado el peso total de la extracción de rentas dinerarias para un pechero abulense en los años centrales del siglo XV. Pero sí podemos retener un orden de magnitud derivado de la documentación analizada: en los tres años de nuestro registro, sólo en concepto de monedas se recaudaron 288 maravedíes por pechero, mientras que dos terceras partes de los préstamos analizados son por un monto menor a 300 maravedíes. Esto puede dar una idea de la incidencia que la recaudación tributaria tiene en el fenómeno del endeudamiento campesino, especialmente por la naturaleza dineraria de extracciones que pesan sobre una economía campesina muy parcialmente mercantilizada ${ }^{25}$.

Por contraste, en el otro extremo de la escala, sólo el $4 \%$ de los préstamos en dinero supera los 2.000 maravedíes (22 casos); incluso poniendo un límite menos estricto, apenas un II\% (63 casos) supera los I.ooo maravedíes, lo que no es una suma en absoluto exorbitante. Hay que señalar además que estos porcentajes se reducirían (aumentando la proporción de deudas menores) si incluyéramos las deudas en grano, que en su abrumadora mayoría son por unas pocas fanegas de cereal. Por añadidura, en muchos de estos casos de deudas mayores se puede identificar con facilidad a los deudores como personajes acomodados, a su vez acreedores de aldeanos insolventes o vinculados a otros negocios importantes ${ }^{26}$;

\footnotetext{
que ambos conceptos suponen criterios distintos de recaudación. Ya hemos mencionado la diferencia en las cuantías mínimas. Además de ello, la mayor parte de los privilegios de exención remiten a las monedas y no al pedido o a otras imposiciones. A esto aluden los procuradores en 1451 cuando señalan que, a causa de que los pecheros más ricos se arman caballeros, disminuyen las rentas regias, sennalada mente enlas monedas... ca por la dicha cabsa non valen oy la meytad o poco mas de aquello por quelas dichas monedas se solian arrendar antes quelos tales pecheros fuesen armados $e$ se armasen caualleros, Cortes, III (1451), pet. 29, p. 613. El pedido, en cambio, supone menos excusados por privilegio, cuantías mínimas más elevadas, y se distribuye por el sistema de cañamas, por el cual primero se determina el monto global a recaudar y luego se deduce lo que corresponde a cada pechero según la valía en que está empadronado; véase DA GracA, Laura, Poder político y dinámica feudal. Procesos de diferenciación social en distintas formas señoriales (siglos XIV-XV), Valladolid, Universidad de Valladolid, 2009, especialmente pp. 130 ss.

24. Para la magnitud del arrendamiento de alcabalas y tercias del Obispado de Ávila, LADERo Quesada, Ob. cit., p. 381 ss.

25. Moreno NúñeZ, José Ignacio, Ávila y su Tierra en la baja Edad Media (siglos XIII-XV), Ávila, Junta de Castilla y León, 1992, p. 245, destaca la escasa vitalidad de los intercambios aldeanos; sobre el efecto oneroso de las obligaciones fiscales por su carácter dinerario, véase BrUmont, Francis, Campos y campesinos de Castilla la Vieja en tiempos de Felipe II, Madrid, Siglo XXI, 1984, p. 198.

26. Mencionemos algunos ejemplos: Alfonso Rodríguez, sastre, acreedor (véase abajo), figura en un caso como deudor por $7.000 \mathrm{mrs}$. (uno de los montos más altos de todo el registro), que debe a Gonzalo Rengifo, a quien Alfonso ha comprado dos heredades por valor de 50.000 mrs. (Catálogo, docs. 1437, 8-12-1450; 1486, 1-1-1451; y 15456-2-1451). Juan González, miembro del clan de los González de San Juan (véase abajo), es en una ocasión deudor del más encumbrado prestamista del registro, Ruy López Beato, por 1400 mrs. (doc. 932, 16-3-1450); Luis González de San Juan, el más prominente de la familia, es codeudor en una ocasión junto a otro gran prestamista, Diego Ordoñez, por 2120 mrs. (doc. 536, 22-4-1449) y deudor en otra ocasión por 1300 mrs. (doc. 1235, 17-8-1450). Juan Díaz, miembro de una importante parentela formada por los descendientes de Xemé Muñoz, entre otras cosas recaudador de los votos del deán y cabildo de Santiago, aparece como deudor de Elvira López por 1.000 mrs. (doc. 20, 9-2-1448). Otro hijo de Xemé Muñoz, Gómez de la Serna, que aparece tomando en arriendo un molino por 100 fanegas de trigo y dando en arriendo heredades y bueyes, figura como deudor por $1766 \mathrm{mrs}$. de Pedro de Peñafiel, empresario textil del que se trata más adelante (doc. 224, 23-8-1448). Martín González, arrendador de la alcabala de la leña de Calzada de la Puente
} 
en ciertos casos es incluso evidente que la deuda en realidad se vincula a la distribución del tributo en el estamento de los privilegiados ${ }^{27}$.

En suma, el análisis de las deudas según sus montos revela la existencia de dos circuitos de crédito claramente diferenciados: por un lado, una abrumadora mayoría de préstamos por cantidades menores, que se corresponden con las características clásicas del endeudamiento campesino, esto es, el consumo y el pago de rentas ${ }^{28}$; por otro lado, una pequeña fracción de las obligaciones, por montos más importantes, que expresa las relaciones entre sujetos pudientes y donde probablemente el dinero dado a crédito esté vinculado a la realización de distintos negocios lucrativos.

Pero la evidencia más clara acerca de la precaria situación de los deudores por contraste con el poder económico de los acreedores, se desprende de la información sobre la concentración de la oferta de préstamo. En efecto, en las 705 obligaciones registradas se contabilizan 670 deudores $^{29}$ frente a 137 acreedores, de los cuales, como veremos enseguida, un pequeño grupo concentra la mayoría de las obligaciones. Pero la concentración del poder económico es también espacial: los prestamistas son, en su abrumadora mayoría, vecinos de Ávila. Hemos encontrado sólo i4 casos que provienen de la Tierra abulense o de otras ciudades, todos ellos prestamistas ocasionales ${ }^{30}$. Por contraste, el origen de los deudores es mucho más disperso y equilibrado: 146 deudores son habitantes de la villa ${ }^{31}$, algo más de uno cada cinco, lo que se explica fácilmente tanto por el peso demográfico del núcleo urbano $^{32}$ como porque se trata del registro de un notario radicado en la ciudad.

y de las doce monedas, aparece como codeudor, junto a Pedro Gómez, platero y también arrendador de rentas, por 1850 mrs. (doc. 1184, 24-7-1450).

27. Fernando González de Bonilla, vasallo del Rey, reconoce deber a Lope de Tapia, guarda del Rey, regidor y vecino de Segovia, $4.000 \mathrm{mrs}$., pero a continuación recibe de éste poder para recaudar más de $8.000 \mathrm{mrs}$. de merced y quitación (Catálogo, docs. 716 y 717, 6-10-1449). Juan Rodríguez, hijo del ya mencionado Xemé Muñoz, figura como deudor por 1780 mrs., pero inmediatamente se reconoce que los ha pagado y que el dinero es una merced en la alcabala del pan de Ávila de la cual Juan Rodríguez es recaudador (docs.371 y 372, 19-12-1448).

28. Enfatizamos, por lo tanto, que el fenómeno no obedece a una causa única y lineal; si hemos dedicado más espacio al análisis de la incidencia de la recaudación de rentas y tributos en el endeudamiento campesino es porque la misma es menos evidente y requiere mayor demostración que el endeudamiento destinado al consumo.

29. Dos factores alteran la paridad entre deudores y deudas: por un lado, como veremos más adelante, muchos sujetos se endeudan más de una vez; por otro, en 128 obligaciones aparecen dos o más personas como deudores, lo que constituye una garantía para el prestamista que eventualmente puede accionar contra los bienes los sujetos obligados. De todos modos, nosotros hemos contado una sola vez 36 préstamos en los que figuran integrantes de un mismo núcleo familiar (marido y mujer, padre e hijo, etc.) que residen en un mismo lugar, dado que presumiblemente se trata de integrantes de una misma unidad doméstica. De discriminar estos casos, el número total de deudores supera los 700, ampliando más aún la diferencia con el número de acreedores registrados.

30. Un vecino de Fontiveros y uno de Arébalo son acreedores en tres préstamos cada uno (Catálogo, docs. 984, 1068,1334, y 113, 130, 943, respectivamente). Con dos préstamos figura un vecino de Cebreros (docs. 109 y 110) y otro de Guadalajara (docs. 673 y 675). Los demás son acreedores una única vez y de diversa procedencia: docs. 13 (El Barraco), 195 (Tordesillas), 568 (Riofrío), 715 (Hontoria), 716 (Segovia), 1004 (Toledo), 1054 (Navalpuerto), 1189 (Medina del Campo), 1433 (Aldeavieja) y 1592 (El Valle).

31. Excluimos de esta cifra a 12 vecinos de Ávila que moran en lugares de la Tierra, e incluimos en ella el caso de 2 moradores en Ávila que no se especifica que sean vecinos.

32. Moreno Núñez, Ob. cit., p. 129, en base al repartimiento de 1490 para la guerra de Granada, estima que la población de la villa alcanza el 12,2\% del total. 
El resto se encuentra desperdigado de modo bastante homogéneo: apenas ocho lugares tienen ro o más deudores (con un máximo de I8) ${ }^{33}$, mientras que otras I8 aldeas presentan entre 5 y 9 deudores ${ }^{34}$. Los demás tomadores de préstamos se encuentran distribuidos en casi dos centenares de aldeas de la Tierra, a razón de I a 4 por cada lugar. Como es lógico, algunos de estos núcleos poblacionales se encuentran en el entorno más próximo a la ciudad, pero esta no es una norma rígida: otros se encuentran, como Adanero o Fuente el Sauz, en el extremo norte de la Tierra, e incluso se registran deudores aislados originarios de aldeas ubicadas en el extremo occidental del territorio ${ }^{35}$.

Por cierto, el origen casi exclusivamente urbano de los prestamistas podría explicarse como una distorsión producto de la documentación analizada. Si quien solicita el préstamo concurre a un acreedor urbano y éste a su vez lo lleva ante el notario para asentar la transacción, es lógico sospechar que en el registro se encuentren sobre representados los acreedores que viven en el mismo lugar que el notario. Es difícil evaluar en qué proporción esta circunstancia puede afectar la representatividad de los datos aquí analizados. En las cartas de espera solicitando el aplazamiento del pago de deudas, por ejemplo, se encuentran varios ejemplos de acreedores de la Tierra, aunque aquí también la mayoría son de origen urbano ${ }^{36}$. Documentos ocasionales también refieren al endeudamiento inter-aldeano ${ }^{37}$.

33. Se trata de: Adanero (13 deudores), Cardeñosa (11), Cebreros (16), Cillán (10), El Barraco (17), Gotarrendura (13), Mingorría (13) y San Bartolomé de Pinares (18).

34. Bermudillo (5), Bernuy Salinero (6), Constanzana (8), El Atizadero (8), El Oso (9), El Herradón (7), El Tiemblo (5), Fuente el Sauz (7), Gemuño (6), Grajos (6), La Nava (9), La Serrada (6), Los Patos (5), Navaluenga (7), Riocabado (5), Riofrío (5), San Martín de Valdeiglesias (7) y Santo Domingo de la Calzada (7).

35. Como Muñopepe o El Hoyo; para la ubicación de las poblaciones del término concejil abulense, véase MARTíNEZ Diez, Gonzalo, Las Comunidades de Villa y Tierra de la Extremadura castellana, Madrid, Ed. Nacional, 1983.

36. LuIs Ló PEZ, Carmelo, Documentación medieval abulense en el registro General del Sello, vol. IX (30-VII-1493 a 17IV-1494), Ávila, Institución Gran Duque de Alba, 1996, doc. 82, 12-4-1494, se menciona un acreedor de Muñomer, tierra de Ávila; CABAÑAs GonzÁlez, María Dolores, Documentación medieval abulense en el registro General del Sello, vol. XIII (18-I-1497 a 22-XII-1497), Ávila, Institución Gran Duque de Alba, 1996, doc. 55, 18-8-1497, se menciona a una acreedora de Cebreros; García Pérez, Juan, Documentación medieval abulense en el registro General del Sello, vol. XV (18-I-1499 a 24-XII-1499), Ávila, Institución Gran Duque de Alba, 1996, doc. 75, 5-10-1499, se menciona un acreedor de Sinlabajos, aldea de Arévalo; García PÉreZ, Juan, Documentación medieval abulense en el registro General del Sello, vol. XVIII (1-I1502 a 30-X-1502), ávila, Institución Gran Duque de Alba, 2007, doc. 111, 6-10-1502, menciona genéricamente entre los acreedores a vecinos de la Tierra junto a otros de la ciudad; lo mismo en HeRnÁndez PIERNA, Juan, Documentación medieval abulense en el registro General del Sello, vol. XI (3-I-1495 a 13-XII-1495), Ávila, Institución Gran Duque de Alba, 1995, doc. 84, 28-7-1495, en relación a judíos conversos. En el contexto de la crisis agraria de principios del siglo XVI (contamos con medio centenar de cartas de espera entre 1503 y 1504), LADERO QUESADA, Manuel, Documentación medieval abulense en el registro General del Sello, vol. XX (22-V-1503 a 30-XI-1503), Ávila, Institución Gran Duque de Alba, 2007, doc. 84, 24-8-1503, menciona deudas entre vecinos de Mombeltrán; doc. 86, 27-8-1503, un acreedor de Magazos, aldea abulense; doc. 105, 4-9-1503; doc. 110, 11-9-1503; doc. 114, 14-9-1503, doc. 120 y 121, 18-9-1503; doc. 126, 28-9-1503; doc. 129, septiembre de 1503; LuIS LóPEZ, Carmelo, Documentación medieval abulense en el registro General del Sello, vol. XXI (1-X-1503 a 30-IV-1504), Ávila, Institución Gran Duque de Alba, 2007, doc. 38, 23-11-1503; doc. 101, 10-3-1504; doc. 102, 11-3-1504; doc. 123, 30-3-1504; DEL SER QUIJANO, Gregorio, Documentación medieval abulense en el registro General del Sello, vol. XXII (1-V-1504 a 31-XII-1504), Ávila, Institución Gran Duque de Alba, 2010, doc. 17, 31-5-1504; todos ellos donde aparecen algunos acreedores aldeanos, con frecuencia junto a otros de Ávila o Arévalo. Véase también CASADO Alonso, Ob. cit., pp. 534-5, donde señala la existencia de labradores acomodados prestamistas pero como grupo minoritario frente a los mercaderes urbanos.

37. Cuando en 1432 el procurador de Álvaro de Luna tomó posesión de los alijares de la Transierra abulense que le habían sido concedidos por Juan II como señorío, se detuvo en distintos puntos para administrar justicia, como parte 
Sin embargo, como revela nuestro registro notarial, queda en pie el hecho de que centenares de campesinos insolventes de la Tierra efectivamente acuden al ámbito urbano a solicitar créditos, lo que puede indicar que no encuentran en sus lugares de origen una oferta suficiente, al menos en una coyuntura crítica como la aquí estudiada. Es incluso significativo que El Barraco, Cebreros y Cardeñosa, tres de los ocho lugares con mayor procedencia de deudores, son identificados por Moreno Núñez como aldeas con cierto desarrollo relativo de los intercambios, lo que haría esperar una mayor vitalidad financiera a nivel local ${ }^{8}$. Esto es congruente, por último, con lo que hemos dicho más arriba respecto del impacto potenciado que tienen las imposiciones en dinero sobre una economía aldeana que, más allá de los avances registrados en el proceso de mercantilización, sigue fuertemente ligada a la producción y el consumo de valores de uso directos.

En resumen, aun aceptando una cierta distorsión producto de la naturaleza de la muestra documental utilizada, la vecindad mayoritariamente urbana de los acreedores parece confirmar el predominio económico de la Villa sobre la Tierra y el consiguiente flujo de excedentes hacia la primera, que se deriva no sólo de los mecanismos de extracción fiscal sino también de las relaciones económicas de subordinación entre sujetos particulares ${ }^{39}$.

Veamos entonces más en detalle quiénes son los individuos que se benefician de esta asimetría y cuáles son sus actividades más importantes.

\section{LOS PRESTAMISTAS}

Como se desprende de la diferencia existente entre el número de deudas y el número de acreedores expuesta más arriba, ciertos sujetos acaparan el préstamo de modo abrumador.

De los I37 prestamistas identificados, la gran mayoría figuran como acreedores en sólo una o dos oportunidades. En cambio, si seleccionamos los acreedores que figuran en ro obligaciones o más, encontramos que I7 individuos concentran 492 préstamos; en porcentajes, el I2\% de los acreedores concentra el 70\% de los préstamos, con un promedio de 29 obligaciones en su favor cada uno. Todos estos prestamistas importantes son vecinos de Ávila. En la cúspide del grupo, si seleccionamos a los acreedores de más de 20 préstamos, encontramos que apenas 7 sujetos (el 5\% del total) concentra 35I deudas en su favor -esto es, el 50\% de los préstamos.

del rito de apropiación. Los siete pleitos ante él presentados que menciona el documento son casos de deudas entre vecinos de la Tierra, tres por préstamos de dinero y cuatro por ventas fiadas de animales, BarRIos García, Ángel; Luis Corral, Fernando; RiAño PÉrez, Eugenio, Documentación medieval del Archivo Municipal de Mombeltrán, Ávila, Institución Gran Duque de Alba, 1996, doc. 23, 26-29/11/1432.

38. Moreno NúÑEZ, ob. cit., p. 245, en base a un documento de finales del siglo XV.

39. FURIó, «Endettement paysan», p. 154. 
Las actividades de estos individuos son de sumo interés. Comencemos por Ruy López Beato, bachiller, quien concentra por lejos la mayor cantidad de préstamos otorgados (I39 obligaciones en su favor). Seguramente su pericia en el tema explique que también recibe encargo para cobrar deudas de terceros ${ }^{40}$. Junto a otros dos sujetos, entre ellos Abrahen Melamed, hermano de Pedro Suárez «el mozo», otro gran prestamista del que hablaremos a continuación, es arrendador de la alcabala de los paños de Ávila y su Tierra ${ }^{41}$. Esto sin duda se vincula a su actividad en el comercio de lana, donde realiza numerosas compras adelantadas ${ }^{42}$. Con idéntico procedimiento compra asimismo otros productos, especialmente mosto, pero también madera y granos ${ }^{43}$. El parentesco entre préstamo y compra adelantada puede graficarse con el caso de Toribio Sánchez, vecino de Gotarrendura, quien recibe un préstamo de Ruy López Beato por 500 mrs. y a continuación se obliga a entregarle io fanegas de pan mediado, lo que además testimonia el brutal incremento de los precios en la coyuntura ${ }^{44}$. Años más tarde, nuestro bachiller también aparece en otro registro notarial arrendando rentas eclesiásticas en San Juan de la Encinilla ${ }^{45}$ y como prestamista del concejo de San Bartolomé de Pinares ${ }^{46}$.

Su calidad de letrado y de sujeto destacado se refleja en su actuación como juez árbitro para dirimir conflictos entre vecinos abulenses ${ }^{47}$. Sin embargo, no es un personaje políticamente prominente de la villa, lo que constituye un patrón común a la mayoría de los acreedores que analizamos. Hemos encontrado otras dos menciones a un Ruy López Beato, bachiller y vecino de Ávila, en la documentación concejil, tres décadas posteriores a los registros notariales que estamos analizando. En ningún caso se vinculan con actuaciones políticas u oficiales, sino con negocios de dudosa naturaleza. La primera es una denuncia de Juan Alfonso,

40. De Fernando González de Bonilla, vasallo del Rey y vecino de Ávila (Catálogo, doc. 28, 15-2-1448) y de Pedro González Abenhihen, vecino de El Colmenar (doc. 209, 6-8-1448).

41. Catálogo, doc. 142, 18-6-1448.

42. Compra 10 arrobas de lana por 1000 mrs. a Pascual Sánchez Torres y a Juan González, vecinos de Cebreros (Catálogo, doc. 684, 12-9-1449); al mismo Juan González le compra en otras dos oportunidades 5 arrobas por 500 mrs. y 2,5 arrobas por 250 mrs. (doc. 1166, 13-7-1450 y doc. 1171, 15-7-1450, respectivamente); a Martín Sánchez, vecino de Villalba, 2,5 arrobas de lana merina y 1 arroba de lana de cordero por 300 mrs. (doc. 1179, 21-7-1450); a Alfonso Sánchez, vecino de El Barraco, 1 arroba de lana por 120 mrs. (doc. 1468, 23-12-1450).

43. Compra a Martín Fernández, vecino de Cabezas de Alambre, 1,5 moyos de mosto y una fanega de cebada por 300 mrs. (Catálogo, doc. 979, 13-4-1450); a Alfonso López, vecino de Jaraices, 3,5 moyos de mosto por 700 mrs. (doc. 1291, 25-9-1450); a Miguel Sánchez, mesonero, vecino de Cebreros, 4 moyos de mosto por 800 mrs. (doc. 1583, 26-2-1451); a García Fernández, vecino de Navaluenga, 5 carretadas de tocones por 450 mrs. (doc. 1252, 4-9-1450); a Mateo Sánchez, vecino de Burgohondo, 2 carretadas de vigones por 120 mrs. (1423, 29-11-1450).

44. Catálogo, doc. 1394 y 1395, ambos del 20-11-1450. Esto daría una proporción de 50 mrs. la fanega de pan mediado (mitad trigo y mitad cebada) para noviembre de 1450, el mes de mayor registro de endeudamientos de toda la serie estudiada. Por el contrario, en enero de 1449 Juan Rodríguez, hijo de Xemé Muñoz, realiza préstamos dando opción a los deudores a pagar en trigo o en dinero, a razón de 30 mrs. la fanega de trigo (docs. 396 a 399, 10-1-1449). Un año más tarde todavía encontramos una compra adelantada de 20 fanegas de cebada por 300 mrs., a razón de 15 mrs. la fanega (doc. 830, 26-1-1451).

45. Registro de Alfonso González de Bonilla, entrada 379, 9-5-1467; Ruy López Beato ya había dado préstamos a vecinos de ese lugar: véase docs. 833, 13-1-1450 y 959, 27-3-1450.

46. Del Ser Quijano, Gregorio (ed.), Documentación medieval del Archivo Municipal de San Bartolomé de Pinares (Ávila), Ávila, Institución Gran Duque de Alba, 1987, doc. 44, 2-7-1467.

47. Catálogo, doc. 111, 25-5-1448. 
vecino de El Tiemblo, quien había arrendado la bellota de la dehesa del valle de Iruelas a dicho concejo por 21.00o maravedís. Como la bellota se perdió, el denunciante dice que no está obligado a pagar cosa alguna, pero quel dicho conçejo e omnes buenos, de que vieron la dicha vellota perdida, vendieron el contrabto que contra él tenían por menos preçio al bachiller Ruy López Beato, vezino en la dicha çibdad, el qual diz que, por ser poderoso y liçençiado, fizo esecuçión en sus bienes, y lo engañó de diversas maneras ${ }^{48}$.

La segunda es también una denuncia por prácticas fraudulentas: Toribio Cimbrón, vecino de Ávila, dice que había empeñado a Ruy López Beato tres yugadas de tierra en Rioforte por çierta quenta de maravedís a pagar en cierto tiempo. Cumplido el plazo, el deudor dice haber acudido con los maravedíes pero el bachiller se negó a recibir el pago y vendió las tierras a Pedro de Ávila, señalado como cómplice de la estafa $^{49}$. No es ocioso señalar que las prácticas por las que se lo denuncia en 1480 guardan una estrecha relación con lo que se puede esperar de un encumbrado prestamista $^{50}$. En cualquier caso, la actuación propiamente política de Ruy López Beato es virtualmente nula: representa una clase media urbana letrada cuyo poder es de naturaleza principalmente económica, fuertemente ligado al comercio y las finanzas y con vínculos constantes con los aldeanos de la Tierra.

Es el mismo perfil de otros acreedores. Pedro Suárez «el mozo», converso, es el segundo prestamista en importancia del registro. Conocemos su entorno familiar más cercano: hermano de Abrahen Melamed, judío arrendador de la alcabala de los paños en sociedad con Ruy López Beato, prestamista ocasional y comprador de tierras de campesinos endeudados ${ }^{5 \mathrm{I}}$; esposo de Urraca Suárez, también conversa, quien actúa junto a él en algunos tratos y a quien otorga poder para ordenar su testamento (lo que tal vez sea indicio de su edad, a despecho de su apodo) ${ }^{52}$; hijo de una tal Ledicia, acreedora, significativamente apodada «la rica» ${ }^{33}$; y padre de Gabriel, quien se está iniciando en el oficio de prestar dinero a logro ${ }^{54}$. Pedro

48. LuIS López, Carmelo, Documentación medieval abulense en el Registro General del Sello, vol. II (20-IX-1479 a 14-XII-1480), Ávila, Institución Gran Duque de Alba, 1995, doc. 16, 21-1-1480, p. 47.

49. Idem, doc. 83, 17-11-1480, p. 199.

50. Por lo demás, una actuación dilatada durante tres décadas tampoco es inusual. Por ejemplo, otro de los prestamistas de los que hablaremos enseguida, Álvaro de Bracamonte, fue titular del señorío de Peñaranda y Fuente el Sol de 1435 a 1485; véase más abajo. Para el campesinado, véase la excelente reconstrucción de la prolongada trayectoria vital de Pere Compte realizada por PAdrós, Ob. cit.

51. Ya hemos mencionado a su hermano Abrahen Melamed, quien aparece como prestamista en cinco oportunidades (Catálogo, docs. 386, 389, 532, 840 y 1071), además de lo que le deben como recaudador de la alcabala de los paños (docs. 169, 492, 495, 1383). Compra de Diego Fernández y de Martín Juan, hermanos, hijos de Domingo Fernández «el orejudo', vecinos de Gotarrendura, 6 obradas en término de El Oso por 660 mrs. (doc. 821, 31-12-1449). Ambos hermanos parecen estar arruinados: Diego Fernández es deudor de Álvaro de Bracamonte por 100 mrs. (doc. 450) y de Ruy López Beato por 550 mrs. (doc. 962); Martín Juan es deudor de Pedro Ordoñez por 40 mrs. (doc. 922) y del mismo Pedro Suárez por 100 mrs. (doc. 952). Abrahen Melamed también compra casas y tierras en término de El Oso de Pedro López, vecino del lugar (doc. 669, 5-9-1449).

52. En Catálogo, doc. 1534, 30-1-1451, Pedro legitima las arras que otorgó a su mujer Urraca Suárez cuando se casaron según la ley abrayca. Sobre su testamento, doc. 1488, 1-1-1451.

53. Catálogo, doc. 540, 23-4-1449.

54. Gabriel aparece como acreedor en dos oportunidades (Catálogo, docs. 556 y 1610). 
aparece como acreedor en 58 obligaciones, aunque su actividad como prestamista y cobrador de deudas para terceros es más amplia todavía 55 .

También desarrolla otros negocios adicionales: compras adelantadas de madera, de zumaque y de pescado ${ }^{56}$, en ocasiones a sujetos que son a la vez deudores suyos $^{57}$ o de otros conocidos acreedores ${ }^{58}$, y algunas operaciones con granos ${ }^{59} \mathrm{e}$ inmuebles ${ }^{60}$. Resultan interesantes las menciones a contrataciones de mano de obra: toma a soldada a una joven ${ }^{6 r}$ y en dos oportunidades contrata a jornal a un carpintero moro, a la sazón deudor suyo, para ciertos trabajos ${ }^{62}$. Estos casos ejemplifican el uso doméstico de asalariados.

Pedro Suárez «el mozo» mantiene relaciones con otro personaje muy presente en el registro: Luis González de San Juan. Pedro le otorga procuración para que actúe en su nombre, una práctica habitual entre sujetos influyentes ${ }^{63}$. En un pleito con el concejo de Burgohondo, por su parte, Luis González, actuando como juez

55. Pedro Suárez recibe poder de Pedro García «el mozo», escribano del Rey, vecino de Ávila, para cobrar deudas (doc. 176, 8-7-1448); lo mismo de Juan López del Arroyo (Catálogo, doc. 1225, 12-8-1450). Otorga carta de pago a Bartolomé Sánchez, vecino de Navalpuerto, de lo que le adeudaba a él y a su madre, excepto 120 mrs. (doc. 540, 23-4-1449); otorga carta de pago a los herederos de Pascual Sánchez Barbudo, vecino de Burgohondo, por cualquier deuda que hubiese tenido con él (doc. 1009, 26-4-1450); lo mismo a Diego García de la Mata, vecino del mismo lugar (doc. 1010, 26-4-1450); Urraca Suárez, en su nombre, otorga carta de pago a Jaco Cohen, judío vecino de Madrigal, por 25 doblas de oro (doc. 553, 7-5-1449). Pedro Suárez también compra deudas de terceros para cobrarlas por su cuenta (doc. 1455, 13-12-1450). Su actividad financiera se extiende a Arévalo, por lo que otorga poder a Mayr Cohen, vecino de dicha villa, para cobrar deudas en Arévalo y su tierra (doc. 1172, 16-7-1450). Estas referencias no están incluidas en las 58 obligaciones en las aparece como prestamista en el período analizado.

56. Compra de Pascual Domingo y Juan Fernández, vecinos de El Barraco, un cargo de vigones por $100 \mathrm{mrs}$ (Catálogo, doc. 370, 18-12-1448); de Juan Sánchez Redondo, vecino de Navalmoral, un cargo de vigones de pino por 50 mrs (doc. 458, 4-3-1449); de Martín Fernández, vecino de El Barraco, medio cargo de terciales y medio de vigones por 80 mrs (doc. 576, 13-6-1449); de Juan Sánchez, vecino de Navarredondilla, 2 cargos de vigones por 150 mrs. (doc. 829, 8-1-1450); de Alfonso García, vecino de Los Casales, 25 arrobas de zumaque por 300 mrs. (doc. 904, 22-2-1450; de Antón Sánchez Galeote, vecino de Villalba, 40 arrobas de pescado por 500 mrs. (doc. 347, 23-11-1448).

57. Miguel Sánchez, vecino de Zorita, se obliga a darle 3 libras de pescado (Catálogo, doc. 912, 27-2-1450); poco después se endeuda con él por $142 \mathrm{mrs}$., una fanega de trigo y media de cebada y además se obliga a darle 2 libras más de pescado por $8 \mathrm{mrs}$. (doc. 1041, 12-5-1450).

58. Juan Sánchez, vecino de Villalba, se obliga a dar a Pedro 10 arrobas de pescado por 15 mrs. que recibió por cada una (Catálogo, doc. 1292, 27-9-1450) y poco después otras 15 arrobas por 18 mrs. recibidos por cada una (doc. 1529, 28-1-1451); para la misma época, Juan Sánchez se endeuda con Ruy López Beato (doc. 1221, 12-8-1450).

59. Catálogo, doc. 619, 14-7-1449; y doc. 623, 15-7-1449.

6o. Catálogo, doc. 613, 9-7-1449; doc. 740, 25-9-1449; y doc. 1245, 25-8-1450.

61. Juan Sánchez del Río, vecino de Navaluenga, pone a soldada a su hijastra Catalina con Pedro Suárez durante 5 años por 600 mrs (Catálogo, doc. 1209, 8-8-1450); el mismo día también pone a soldada a su hijo Juan con Diego González de San Juan, durante 10 años por 1000 mrs (doc. 1210, 8-8-1450). Esto supone una separación del núcleo familiar, ya que Juan Sánchez del Río sigue viviendo en Navaluenga: dos meses más tarde recibe poder de Juan González, hijo de Diego González de San Juan, para prendar a personas y ganados que entrasen en una viña suya, sita en dicho lugar (doc. 1343, 20-10-1450) Como veremos enseguida, el clan familiar de los González de San Juan tiene fluidas relaciones con Pedro Suárez «el mozo».

62. Alí de la Rua, carpintero, moro, vecino de Ávila, se obliga a devolver a Pedro Suárez 250 mrs. recibidos en préstamo y a dos días de lana a su oficio de carpentero por 30 mrs. que recibió de jornal (Catálogo, doc. 903, 21-2-1450); y nuevamente a hacer ciertos trabajos de carpintería y le labrar cinco días de lana por 500 mrs. (doc. 1300, 1-10-1450).

63. Catálogo, doc. 256, 19-9-1448. En otra oportunidad, Pedro Suárez y Luis González reciben conjuntamente procuración de un tercero, Pedro Jimeno, vecino de Navalpuerto (doc. 1055, 20-5-1450). Pedro Suárez también da y recibe poderes de otros personajes: doc. 233, 2-9-1448; doc. 658, 26-8-1449; doc. 966, 31-3-1450; doc. 1224, 12-8-1450; doc. 1363, 2-11-1450. 
árbitro junto a otro vecino, sentencia que dicho concejo pague a Pedro Suárez 2400 mrs. $^{64}$.

Abramos un breve paréntesis: Luis González de San Juan, aunque no sea un prestamista especialmente prominente, merece una mención por la diversidad de actividades financieras que desarrolla. Acreedor en I7 oportunidades, la mayor partes de sus tratos se vinculan sin embargo a otros negocios: es recaudador de tributos regios (monedas y tercias) ${ }^{65}$, cobrador en nombre de otros prestamistas y recaudadores ${ }^{66}$, traficante de $\mathrm{sal}^{67}$, arrendador de la alcabala del pan y del pescado de la ciudad de Ávila ${ }^{68}$, y arrendador de la alcabala de la sal junto a Pedro López, otro negociante acomodado ${ }^{69}$. Uno de sus hijos, Pedro González de San Juan, lo ayuda en la recaudación de la alcabala ${ }^{70}$, mientras otro, Diego, se inicia como prestamista y comerciante de sal ${ }^{71}$. El registro presenta también información de otros González de San Juan, en lo que parece un clan familiar de negociantes, que acumulan otra veintena de préstamos y numerosos negocios conexos ${ }^{72}$. Uno de ellos, Diego González de San Juan, se desempeñará como procurador de los hombres buenos pecheros en repetidas oportunidades desde $1453 \mathrm{y}$ al menos por dos décadas ${ }^{73}$.

64. Catálogo, docs. 488 y 489, ambos del 17-3-1449.

65. Otorga poder a Diego de Ávila para recaudar las 12 monedas del concejo de Horcajuelo (Catálogo, doc. 249, 18-9-1448); a Alfonso López, para recaudar las 12 monedas del concejo de Santa María de Robledo (doc. 269, 27-9-1448). Pedro Martín, vecino de Piedrahitilla, se obliga a pagarle 66 mrs. del pecho de las 12 monedas (doc. 294, 8-10-1448) y otros 22 mrs. correspondientes al pecho de su madre (doc. 295, 8-10-1448); Pedro Sánchez, vecino de Cillán, se obliga a pagarle 70 mrs. por el mismo concepto (doc. 296, 9-8-1448); Juan Alfonso y Juan Muñoz, vecinos de Molinero, se obligan en 192 mrs. por el mismo concepto (doc. 316, 25-10-1448). Otorga poder para la recaudación de tercias reales atrasadas (doc. 835, 14-1-1450). Junto a Mosé de Muño, cobra tercias del lugar del Flores correspondientes al año 1448 (docs. 1016 a 1019, 29-4-1450).

66. Pedro Guillén de Sevilla, vecino de Ávila, escribano y arrendador de las salinas de Atienza, le otorga poder para cobrar deudas (Catálogo, doc. 65, 2-3-1448), y para inspeccionar lo referido a la entrada de sal (doc. 66, 2-3-1448; doc. 454, 3-3-1449). Pedro de Peñafiel, acreedor de 11 préstamos, le otorga procuración y poder para cobrar deudas (doc. 461, 5-3-1449). Recibe procuración de Diego Ordoñez, prestamista del que hablaremos a continuación (doc. 731, 11-10-1449).

67. Contrata carreteros para que le traigan diversas cantidades de sal de Atienza, pagando transporte y portazgos (Catálogo, doc. 639, 6-8-1449; doc. 642, 13-8-1449).

68. Arrendador de la alcabala del pan de la ciudad de Ávila del año 1449 junto a Juan Núñez, escribano (Catálogo, docs. 671 y 672, ambos del 6-9-1449; doc. 820, 24-12-1449) y a Pedro González de Alponte, prestamista del que hablaremos a continuación (doc. 763, 12-11-1449). Arrendador de la alcabala del pescado junto a García González de Córdoba (doc. 1495, 13-1-1451 y doc. 1597, 27-2-1451).

69. Rodrigo Álvarez de Turiel se compromete a pagarles $2500 \mathrm{mrs}$. de la alcabala de la sal que vendió en la ciudad de Ávila durante 1449 (Catálogo, doc. 781, 22-11-1449). Pedro López aparece vinculado a Pedro de Ávila, señor de Villafranca y Las Navas (docs. 40, 20-2-1448 y 46, 25-2-1448), como acreedor (docs. 104, 16-5-1448 y 151, 21-6-1448), comerciando con sal (doc. 186, 19-7-1448) y alquilando un establo en la calle Andrín (doc. 668, 4-9-1449). El mencionado Rodrigo Álvarez de Turiel traspasa a Luis González la tercera parte de la renta de los çoçuelos de la sal en el precio y condiciones que la tenía arrendada (doc. 869, 9-2-1450).

70. Catálogo, doc. 1265, 11-9-1450.

71. Diego aparece como acreedor en Catálogo, doc. 859, 1-2-1450, y doc. 1451, 11-12-1450. Manda traer 4 cargas de sal de Atienza por 860 mrs. y dos fanegas de sal en concepto de transporte (doc. 147, 19-6-1448).

72. La parentela incluye a otro Diego González de San Juan (véase nota siguiente), recaudador de los votos del deán y cabildo de Santiago, con 7 préstamos y a sus hijos Pedro y Juan González, que acumulan 17 préstamos, entre otros negocios.

73. El nombramiento, con comisión especial para atender la restitución de comunales, figura en BARRIOS GARCíA, Ángel et al., Documentación del Archivo Municipal de Ávila (1256-1474), Ávila, Institución Gran Duque de Alba, 1988 (en adelante: Documentación de Ávila), doc. 66, 12-9-1453; diversas actuaciones en idem, docs. 67, 15-9-1453; 72, 28-2-1454; 
En cambio, de nuestro tercer prestamista, Álvaro de Bracamonte, señor de Peñaranda y Fuente el Sol hasta su muerte en $\mathrm{I} 485^{74}$, no tenemos información adicional significativa en el libro del notario. Acreedor de 43 obligaciones de préstamo, sólo aparece en el registro otras dos veces, realizando compras de pescado y madera ${ }^{75}$. Por su jerarquía social, en cambio, aparece como era de esperar repetidas veces en la documentación del concejo ${ }^{76}$.

El siguiente prestamista en importancia, Pedro González de Alponte, concentra 34 obligaciones de deuda en su favor. En este caso tampoco contamos con mucha información adicional, pero sí de algunos vínculos con personajes que ya conocemos: alquila de Pedro Suárez «el mozo» un granero y es arrendador, junto a Luis González de San Juan, de la alcabala del pan de Ávila ${ }^{77}$. A su vez, Pedro González de Alponte da en alquiler unas casas en la calle llamada Cal de Andrín a Juan de Bellacalza, tundidor y pequeño prestamista abulens $\mathrm{e}^{78}$. Por último, compra lana a uno de sus deudores ${ }^{79}$.

Dos hermanos, Pedro Ordoñez y Diego Ordoñez, hijos de Rodrigo Ordoñez, ocupan los siguientes lugares en nuestra lista de prestamistas, con 3I y 25 obligaciones en su favor, respectivamente.

Las numerosas actividades adicionales de Pedro son de sumo interés. Al igual que otros prestamistas, se dedica a la recaudación de tributos regios: cobra alcabalas, tercias y monedas en diversos lugares de la Tierra ${ }^{80}$. De sus actividades

79, 30-6-1460; 80, 30-6-1460; 91, 2-9-1468; 96, 26-2-1474. Se lo menciona a veces como procurador de la ciudad y la tierra a secas, aunque en ocasiones se especifica de los omes buenos pecheros de los pueblos de la dicha çibdad e su tierra, por ejemplo en doc. 79, p. 167. De hecho en este documento y el siguiente, él y otros procuradores de los pecheros se enfrentan a las autoridades del concejo en relación a la forma en que debían pagarse gastos extraordinarios. También figura como testigo de otras actuaciones del concejo en docs. 82, 24-1-1463 y 89, 3-6-1468.

74. Su sobrino pide como heredero que se haga inventario de sus bienes en RGS, vol. IV, doc. 16, 17-12-1485. Véase también Herrero Jiménez, Mauricio, Padrones y registros notariales abulenses en el Archivo de la Real Chancillería de Valladolid, Ávila, Institución Gran Duque de Alba, 2010, «Introducción», p. 45.

75. Pedro García, vecino de El Atizadero, se obliga a darle 32 arrobas de pescado a 15 mrs. la arroba (Catálogo, doc. 1269, 11-9-1450); Juan García Palomo, vecino del mismo lugar, se obliga a entregarle 5 cargas de ripia a razón de 8 mrs. la carga (doc. 1411, 25-11-1450).

76. Con más frecuencia aparece en algunos deslindes de términos limítrofes a su señorío: Documentación de Ávila, docs. 62, 2-5-1453; 84, 3-2-1465; 87, 21-1-1467; Documentación de Ávila II, doc. 268, 15-3-1480 a 1-8-1480; también se lo menciona como regidor del concejo en doc. 289, 24-5-1481. Sobre otro proceso por límites entre sus tierras y las del cabildo de la iglesia de Ávila, SOBRINo CHOMón, Tomás, Documentación medieval abulense en el Registro General del Sello, vol. III (15-XII-1480 a 15-VIII-1485), Ávila, Institución Gran Duque de Alba, 1993, doc. 10, 31-7-1483. Sobre abusos que habría cometido en la construcción de una fortaleza en Fuente el Sol, RGS, vol. IV, doc. 37, 4-4-1486 (los hechos denunciados habrían ocurrido puede aver quinze años, p. 85). Véase Franco SILVA, Alfonso, «Los señoríos de Oropesa y de Peñaranda de Bracamonte», en Del Ser QuiJano, Gregorio (ed.), Historia de Ávila III. Edad Media (siglos XIV-XV), Ávila, Institución Gran Duque de Alba, 2006. Una detallada reconstrucción de todo el linaje en LóPEZ FERNÁNDEZ, M. Isabel, La arquitectura del siglo XVI en Ávila: la casa de Bracamonte y el patrimonio abulense, Tesis Doctoral, Universidad de Salamanca, 2011, Cap. 2.

77. Catálogo, doc. 1245, 25-8-1450 y doc. 763, 12-11-1449, respectivamente.

78. Catálogo, doc. 226, 25-8-1448. La calle Cal de Andrín se ubica entre el Mercado Chico y el Mercado Grande de la ciudad; véase el mapa en LEÓN TELLO, Ob. cit., p. 189. Juan de Bellacalza vuelve a alquilar casas en la misma calle en doc. 565, 6-6-1449; a su vez, figura como acreedor en seis oportunidades (Catálogo, docs. 423, 521, 563, 607, 712 y 1161).

79. Catálogo, docs. 1604 y 1605, ambos del 4-3-1451. El deudor, Juan Sánchez, vecino de Amavida, es también codeudor, junto a otro vecino del lugar, de Ruy López Beato (doc. 1135, 30-6-1450).

80. Juan Sánchez de Garrosa, vecino de Silleros, se obliga a pagarle $50 \mathrm{mrs}$. y un par de pollos por las 12 monedas de ese año (Catálogo, doc. 690, 16-9-1449). En un acuerdo con el concejo de Ferrand-Gallego, los vecinos se obligan a 
comerciales sabemos que vende vino al por mayor ${ }^{8 \mathrm{I}}$, comercia con paños y compra lana ${ }^{82}$. También contrata a soldada un acemilero durante un año, lo que sin duda se relaciona con necesidades derivadas de sus cotidianas actividades comerciales ${ }^{83}$. Compra ladrillos y tejas en Ávila, probablemente para su propia residencia urbana ${ }^{84}$, pero también construye unas casas y un corral tapiado en Aldeanueva de Mora$\tilde{n} a^{85}$. Otros registros lo vinculan fuertemente a la explotación como propietario ausentista de la actividad agraria de la Tierra. Da en arriendo tierras y animales de labor a campesinos de distintas aldeas ${ }^{86}$, en ocasiones a deudores suyos ${ }^{87}$, lo que da una idea de la diversidad y diseminación de sus propiedades agrarias.

Su hermano Diego Ordoñez, por su parte, realiza actividades similares aunque en menor escala. Otorga y recibe poderes para cobrar deudas de terceros ${ }^{88}$; compra lana ${ }^{89}$, ganado ovino y bovino ${ }^{90}$ y sal ${ }^{91}$; posee también heredades y animales de labor que da en arriendo ${ }^{92}$.

pagarle cada uno una fanega de centeno y un par de gallinas cada año, correspondientes al pago de alcabalas y tercias (doc. 861, 2-2-1450). Realiza un acuerdo similar con el concejo de Pedrosillo (doc. 1049, 19-5-1450). En un acuerdo más oneroso, los de concejo de Vicolozano se obligan a entregarle $320 \mathrm{mrs}$., dos pares de gallinas y una carga de paja trigaza cada uno, correspondientes a las alcabalas de ese año (doc. 1090, 11-6-1450).

81. Ventas por un total de 380 cántaras en Catálogo, docs. 190 y 191, ambos del 29-7-1448.

82. Juan Sánchez del Hoyo, vecino de Navalperal, se obliga a entregarle 35 arrobas de lana merina y los añinos, por lo que recibe a cuenta 3211 mrs. (Catálogo, doc. 1268, 24-9-1450). Aparece como acreedor de ciertos paños en doc. 918, 7-3-1450.

83. Catálogo, doc. 1220, 11-8-1450.

84. Hamad y Huzmen, moros, vecinos de Ávila, se obligan a entregarle 3000 ladrillos y 1000 tejas por razón de 800 mrs. que recibieron por ello (Catálogo, doc. 1524, 26-1-1451).

85. Para lo cual contrata a dos vecinos de Hortigosa de Moraña, a quienes paga a cuenta $300 \mathrm{mrs}$. (Catálogo, doc. 1085, 5-6-1450); inmediatamente después registra un préstamo a otro vecino de la misma aldea que bien puede ser hermano de uno de los recién contratados (doc. 1086, 5-6-1450).

86. Pedro García, vecino de Burguillo, tiene arrendado de Pedro unas casas con corral, donde se obliga a realizar ciertas mejoras (Catálogo, doc. 691, 16-9-1449). Esteban López y Juan Fernández, vecinos de Duruelo, le arriendan un par de bueyes y la mitad de una heredad de pan llevar en dicha aldea, durante 6 años, por 30 fanegas de centeno de renta anual (doc. 1215, 10-8-1450). Bartolomé Sánchez de Galisancho, vecino de Palacios, anula los arrendamientos que tenía de Pedro en El Burguillo y Palacios, obligándose a pagarle lo que le debe de rentas (doc. 1493, 8-1-1451).

87. Alonso García, vecino de Yonte, deudor de Pedro Ordoñez por 500 mrs., le arrienda un buey por un año, por 9 fanegas de pan terciado de renta (Catálogo, docs. 1309 y 1310, 2-10-1450). En similar situación, dos vecinos de Santo Domingo de la Calzada le arriendan 3 mulos y un novillo durante un año por 200 mrs. (docs. 1133 y 1134, 30-6-1450); ambos aparecen en varias ocasiones anteriores como deudores de prestamistas conocidos (docs. 724, 765, 770 y 807 ). En cambio, Bartolomé Sánchez, vecino de Palacios, sentenciado a entregarle 60 ovejas como garantía de una deuda, las conserva a renta para Pedro, por 4 años, obligándose a entregarle dos corderos e tres quesos e cuatro bellocines de lana de renta anual (docs. 897 y 898, ambos del 16-2-1450, y 901, 20-2-1450).

88. Catálogo, doc. 326, 1-11-1448 y doc. 578, 18-6-1449.

89. Toribio Sánchez y Martín Fernández, hermanos, vecinos de El Herradón, se obligan a darle 17 arrobas de lana por $1500 \mathrm{mrs}$. que recibieron por ellas (Catálogo, doc. 168, 4-7-1448); el primero de estos hermanos aparece como deudor en otras ocasiones (docs. 659 y 1176 a 1178 ).

90. Martín García, vecino de Riofrío, se obliga a darle un novillo por razón de 500 mrs. que le había pagado (Catálogo, doc. 76, 27-3-1448); Álvaro Jiménez se obliga en iguales condiciones a darle dos novillos por 800 mrs. (doc. 259, 20-9-1448). Juan Sánchez, vecino de Galisancho, recibe $150 \mathrm{mrs}$. y se obliga a entregarle 4 ovejas con 4 corderos (doc. 363, 13-12-1448); luego aparece como deudor de 85 mrs. (doc. 1185, 26-7-1450).

91. Diego Ordoñez se obliga a pagar a Rodrigo Álvarez de Turiel $4800 \mathrm{mrs}$. correspondientes a la compra de sal (Catálogo, doc. 790, 1-12-1449). Pedro de Guillén se obliga a dar a Diego 100 fanegas de sal en pago de una mula que le compró (doc. 895, 15-2-1450).

92. Reconoce haber cobrado de Juan García de Cuellar, vecino de Ávila, la parte de la renta que le corresponde por una heredad y unos bueyes que tenía arrendados de Diego (Catálogo, doc. 1319, 5-10-1450). También tiene tierras 
El séptimo y último acreedor en más de 20 préstamos es un sastre, Alfonso Rodríguez. Con 2I obligaciones en su favor, sus negocios son más modestos que los de los sujetos anteriores; por ejemplo, a diferencia de ellos, no aparece como recaudador de impuestos ni cobrador de deudas para terceros en ninguna oportunidad. Sí realiza, en cambio, operaciones importantes de compra de heredades en la aldea de Blascogarcía a un vecino de Ávila ${ }^{93}$. En otros rubros, en septiembre y octubre de 1450 realiza cuatro compras adelantadas de mosto por un total de I250 mrs, tres de ellas a vecinos de Adanero y dos de ellas a deudores suyos o de otros prestamistas ${ }^{94}$. También adelanta dinero para comprar leña, madera y lana de forma ocasional ${ }^{95}$. En dos oportunidades aparece vendiendo puercos a habitantes de la Tierra ${ }^{96}$; a su vez, uno de sus compradores, vecino de Horcajuelo, pone a su hija a soldada con él, durante dos años, a cambio de 8 varas de paño y 350 mrs ${ }^{97}$. Por último, percibe la renta de unas casas en las cercanías del mercado abulense que le han sido cedidas en prenda como garantía de un préstamo, práctica inusual que se explica por el carácter relativamente importante de la deuda en cuestión ${ }^{98}$.

Por debajo de este selecto grupo de acreedores aparece otro grupo de acreedores relativamente menores. Algunos están emparentados entre sí, como los González de San Juan, a los que ya hemos hecho referencia, o los descendientes de Xemé Muñoz $^{99}$. De otros no tenemos más informaciones que su papel de prestamistas ${ }^{\text {Ioo }}$. De Elvira López, que acumula io obligaciones en su favor, sólo sabemos que es

en Tejares, donde cobra a un vecino de Fuentes Claras por el paso de sus ovejas guardando el prado e el exido (doc. 646, 15-8-1449) y también arrienda unas obradas (doc. 725, 9-10-1449).

93. Gonzalo Rengifo, vecino de Ávila, le vende una heredad en Blascogarcía por 11.100 mrs., de la que inmediatamente le arrienda la hierba por 300 mrs. anuales; Alfonso Rodríguez, a su vez, le reconoce el derecho de retroventa, reservándose las rentas de la hierba y el pan (Catálogo, doc. 1350, 1351 y 1352, todos del 23-10-1450). En los tres meses siguientes se consignan otras operaciones similares entre ambos, por montos de 20.000 y 30.000 mrs. (docs. 1437 y 1438 , del 8-121450; doc. 1486, 1-1-1451). Gonzalo Rengifo termina renunciando al derecho de retroventa a cambio de 7.000 mrs. (docs. 1544 y 1545, del 6-2-1451). Es difícil saber si se trata de tierras distintas en cada operación o de la compra sucesiva de derechos de renta sobre un mismo conjunto de heredades.

94. Compra 2 moyos y medio de mosto por 500 mrs. a Juan Sánchez y Pedro Fernández, vecinos de Adanero (Catálogo, doc. 1274, 18-9-1450); Juan Sánchez es a su vez deudor de Juan Álvarez del Barco, vecino de Ávila, por 600 mrs. (31-10-1449). Compra a Fernando García Chamorro, vecino de Adanero, medio moyo de mosto por 100 mrs. (doc. 1275, 18-9-1450). Compra a Pascual Sánchez, vecino de Adanero, un moyo y medio de mosto por 300 mrs. (doc. 1304, 2-10-1450); Pascual es a su vez deudor suyo por $100 \mathrm{mrs}$. (doc. 1064, 28-5-1450) y de Gil Rodríguez, entregador, vecino de Ávila, por 2 fanegas y media de cebada (doc. 1254, 4-9-1450). Por último, compra a Diego Martín, vecino de Velamuñoz, 2 moyos de mosto por 350 mrs. (doc. 1323, 8-10-1450).

95. Compra a Martín Fernández, vecino de El Cid, 20 cargas de leña de encina por 150 mrs. (Catálogo, doc. 999 , 21-4-1450); a tres vecinos de Navalmoral, 2 cargos de vigones y uno de quinzales de roble por 120 mrs. (doc. 1421, 28-111450); por último, compra a Mingo García, vecino de Las Navas, 4 arrobas de lana contados once velloçinos buenos con su halda por cada arrova por 500 mrs. (doc. 1476, 30-12-1450).

96. Catálogo, doc. 796, 7-12-1449 y doc. 800, 10-12-1449.

97. Catálogo, doc. 1011, 27-4-1450.

98. Se trata de la deuda de Çag Amenamen, judío, vecino de Ávila, por 3000 mrs., quién le alquila las casas que él mismo cede en prenda, por 600 mrs. durante un año (Catálogo, docs. 1076 y 1077, ambos del 2-6-1450).

99. Se trata de sus hijos Fernando Jiménez (un préstamo), Juan Rodríguez (15 préstamos) y Ruy Díaz (7 préstamos) y Gómez de la Serna; entre los nietos figura Juan Díaz, hijo de Ruy Díaz (4 préstamos) y Ruy González. Al igual que los personajes ya vistos, son recaudadores de rentas, realizan compras adelantadas, dan en arriendo casas y heredades, etc.

100. Se trata de Diego de Robledo (18 préstamos) y de Blasco González (15 préstamos). Este último presenta la particularidad de ser el único prestamista cuyos deudores son principalmente vecinos de Ávila. 
viuda de un trapero y que posee sentencia favorable para cobrar otras deudas ${ }^{\text {Ior }}$. Pero en algunos casos encontramos un perfil más definido. Por ejemplo, Antón Rodríguez de León, bachiller, acreedor en I3 obligaciones, se destaca por dar en arriendo en varias oportunidades animales de labor con sus aperos, ganado vacuno, casas y heredades ${ }^{\mathrm{Io2}}$; también actúa como cobrador de deudas para un regidor abulense $\mathrm{I}^{\mathrm{0} 3}$. Se trata de un personaje que, por su formación profesional, aparece algunas veces en la documentación oficial del concejo, como testigo ${ }^{\mathrm{r} 04}$ pero con el tiempo también en encargos de mayor relevancia ${ }^{105}$. Otro letrado, Fernando López de Ávila, escribano del rey, prestamista en I2 oportunidades, resalta en cambio por su actividad como procurador: recibe poderes de representación en una treintena de ocasiones, entre otros de nuestro ya conocido Pedro Suárez «el mozo»; probablemente haya sido también procurador del concejo ${ }^{\text {ro6 }}$. No es el único caso de un escribano que, siendo un prestamista relativamente menor, se desempeña principalmente en calidad de letrado: Fernando González Daza ${ }^{\mathrm{I07}}$ y Alfonso González del Lomo, a la sazón procurador del concejo en $1453^{\text {I08 }}$, son ejemplos adicionales al respecto.

101. Catálogo, doc. 809, 17-12-1449; también que contrata a un joven para que more con ella y le sirva como acarreador (doc. 1316, 4-10-1450).

102. Catálogo, docs. 270, 27-9-1448; 302, 15-10-1448; 361, 12-12-1448; 599, 29-6-1449; y 740, 25-10-1449.

103. Recibe poder de Diego Álvarez Paño, regidor, para cobrar deudas en su nombre: Catálogo, doc. 221, 22-8-1448. Actúa también como juez árbitro junto a nuestro conocido Ruy López Beato en doc. 111, 25-5-1448.

104. Documentación de Ávila, docs. 74, 3-5-1454 y 105, 4-11-1474.

105. Documentación de Ávila II, doc. 160, 2-6-1475, como parte de una comitiva que recibe a la reina Isabel en la ciudad; doc. 164, 14-7-1475, como testigo pero en un delicado conflicto sobre un repartimiento extraordinario que provoca disturbios; doc. 168, 22-9-1475, como representante de Ávila junto al regidor Gonzalo del Peso para establecer una concordia con la ciudad de Segovia en defensa de ambas villas.

106. Es probable que se trate del mismo Fernando López de Ávila, escribano del rey que, también apodado en el mismo documento como Fernando López «el viejo», figura como procurador del concejo en Documentación de Ávila II, doc. 217, 17-2-1477 y 1-3-1477 (p. 272). En el Registro de Alfonso González de Bonilla aparecen mencionados, entre 1465 y 1468, Fernando López «el viejo» y Fernando López «el mozo», también escribano del rey; probablemente se trate de su hijo, heredero del cargo, o eventualmente de dos colegas homónimos a los que se distingue por el apodo. En cualquier caso están vinculados: se los menciona conjuntamente en la entrada $n^{\circ} 49$; véase también las entradas $n^{\circ}$ $42,77,122,327,421$ y 627, que mencionan a uno u otro. Fernando López «el mozo» también aparece en Documentación de Ávila II, doc. 133, 9-2-1475, como procurador de ciertos vecinos de Cebreros que se dicen exentos de pechar, y en doc. 150, 8-5-1475, como testigo.

107. Escribano público y vecino de Ávila, acreedor de 7 préstamos, también presente en la documentación del concejo: Documentación de Ávila, como testigo, en docs. 99, 8-6-1474 y 100, 17-6-1474. Ya había muerto para inicios del año siguiente, lo que desata un pequeño conflicto entre dos aspirantes rivales a ocupar la escribanía pública vacante: Documentación de Ávila II, docs. 145, 27-4-1475; 148, 3-5-1475; 149, 6-5-1475; 150, 8-5-1475; 154 y 155, ambos del 9-5-1475. Se menciona una escritura suya de compraventa en el Registro de Alfonso González de Bonilla (entradas ${ }^{\circ} 244$ ) y unas casas suyas linderas con otras de la iglesia de San Vicente dentro de la dicha çibdad, debaxo de la rrúa de los Çapateros (entrada $n^{\circ}$ 592, p. 237). Fernando González Daza también había autenticado una sentencia favorable al concejo respeto de la restitución de ciertos términos comunes, citada posteriormente en LuIs LóPEz, Carmelo, Documentación del Archivo Municipal de Ávila, vol. III (1478-1487), Ávila, Institución Gran Duque de Alba, 1999, doc. 308, 21 al 26-2-1484, como parte del acto de toma de posesión de los mismos.

108. Acreedor en apenas 4 oportunidades, pero con más de 40 otorgamientos de poderes de representación en su favor por parte de personajes destacados de los negocios y la política local: Abrahem Melamed y Ruy López Beato; los regidores Diego Álvarez Paño y Blasco Núñez; Juan Díaz (del clan de los descendientes de Xemé Muñoz); Pedro de Peñafiel (de quien hablamos a continuación), etc. Se lo menciona como procurador de los pueblos de la ciudad y su tierra en Documentación de Ávila, doc. 64, 26-5-1453. En el Registro de Alfonso González de Bonilla, recibe procuración en 1467 de parte de un clérigo, junto a Fernando López «el mozo», al que mencionamos en una nota anterior (entrada 327). Algunos años más tarde, aun siendo vecino de la villa, brinda sus servicios a pecheros de la tierra: es procurador del 
Mención especial merece Pedro de Peñafiel, también bachiller, tañedor de cámara del Rey ${ }^{\mathrm{I0} 9}$, acreedor de II préstamos y vinculado con otros negociantes ${ }^{\mathrm{IIO}}$, quien aparece desarrollando actividades propias de un verdadero empresario textil $^{\text {III }}$. Posee ovejas merinas que da en arriendo para su pastoreo a cambio de parte de las crías y los esquilmos ${ }^{12}$ y compra lana adelantada ${ }^{\mathrm{II}}$, pero sobre todo aparece contratando en varias oportunidades mano de obra para tejer paños en su casa, especialmente aprendices ${ }^{\mathrm{II} 4}$ pero también artesanos formados ${ }^{\mathrm{II}}$. Si bien hemos visto que varios prestamistas se dedican al comercio de la lana, Pedro de Peñafiel es el único que aparece con un perfil definido en el ámbito de la producción textil.

\section{CONCLUSIONES}

Del análisis anterior puede extraerse algunos elementos de carácter general. Ante todo, el conjunto de relaciones de préstamo analizadas se vincula con las características básicas de la estructura social feudal. Los deudores son en su inmensa mayoría pecheros de la villa o de las aldeas, que toman préstamos para satisfacer el pago de rentas y para afrontar la subsistencia cotidiana en una coyuntura agraria crítica. La imposición de extracciones dinerarias sobre una economía de ritmo estacional y de rendimientos productivos azarosos permite explicar las características de este endeudamiento. Sólo una fracción menor de los créditos, los de mayores montos, revela un patrón distinto, a saber: la circulación del dinero en el marco de las redes de negocios de los sectores pudientes del concejo.

El análisis de los prestamistas, por su lado, muestra las actividades que caracterizan a esa elite. Un pequeño grupo de sujetos concentra la oferta de dinero:

concejo de Cebreros en el pleito ya mencionado contra los pretendidos exentos representados por el mismo Fernando López «el mozo» y ofrece su casa en Ávila para que el procurador de El Hoyo reciba notificaciones allí: Documentación de Ávila II, docs, 133, 9-2-1475 y 169, 28-10-1475, respectivamente.

109. Todavía se desempeñaba en ese oficio una docena de años más tarde: LADERO QueSADA, Miguel Ángel, «1462: Un año en la vida de Enrique IV, rey de Castilla», En la España medieval, 14 (1991), p. 246.

110. Otorga poder de procuración para pleitear, sustituir y cobrar deudas en su nombre a Luis González de San Juan (Catálogo, doc. 461, 5-3-1449) y a otros personajes destacados (docs. 862, 3-2-1450 y 1102, 18-6-1450).

111. Véase DiAgo HERNANDO, Máximo, «El problema del aprovisionamiento de lana para la manufactura pañera castellana a fines de la Edad Media», Anuario de Estudios Medievales, 38/2 (2008), p. 661, en base a la misma documentación notarial que aquí utilizamos.

112. Se trata de 180 ovejas: Catálogo, docs. 138, 14-6-1448 y 465, 7-3-1449, donde reduce de dos a un tercio el porcentaje de producto a cobrar como renta, probablemente como consecuencia de la carestía imperante. Otro contrato por el pastoreo de una vaca y un becerro a cambio de la mitad de las crías en doc. 624, 15-7-1449

113. Catálogo, docs. 435, 14-2-1449 y 910, 26-2-1450.

114. Catálogo, docs. 292, 8-10-1448; 558, 29-5-1449; 703, 23-9-1449; 1262, 10-9-1450; 1330, 12-10-1450; y 1367, 4-111450. En todos estos casos el contrato es suscripto por el padre (ocasionalmente la madre) del aprendiz, y se explicita que éste debe aprender el oficio de tejer paños.

115. Contrata a Juan de Sevilla, pelaire, morador en Ávila, durante un año por 1.200 mrs. (Catálogo, doc. 334, 4-111448) y a otros tres pelaires (doc. 329, 2-11-1448). Uno de estos últimos, Lope de Astudillo, es a su vez deudor en tres ocasiones, dos de ellas con Alfonso Rodríguez, sastre prestamista de quien ya hemos hablado (docs. 644, 15-8-1449; 1078 , 3-6-1450 y 1124, 26-6-1450). 
todos ellos son cristianos, incluyendo un converso (Pedro Suárez «el mozo») ${ }^{116}$, y vecinos de la villa, aunque sus clientes provengan en gran medida de la Tierra. Se caracterizan por la diversidad de sus actividades comerciales ${ }^{117}$, en especial en el mercado de la lana, y financieras, incluyendo muy a menudo el arrendamiento de la recaudación de rentas. Además, el análisis revela la existencia de frecuentes vínculos entre ellos, que se plasman no sólo en la participación conjunta en ciertos emprendimientos económicos sino también en el entrecruzamiento de poderes de representación legal entre varios miembros del grupo ${ }^{\text {II8 }}$. El hecho de que frecuenten al mismo notario para registrar sus tratos puede no ser ajeno a la conformación de estas redes de negocios y afinidades.

En cuanto a su posición social, a excepción de Álvaro de Bracamonte, titular de señoríos, y de Pedro de Penafiel, que cumple funciones en la cámara regia, no hay indicios que indiquen su pertenencia a los sectores privilegiados. Es más, excepción hecha de algunos prestamistas menores que aparecen como procuradores del concejo y de los pecheros abulenses, no hay registro de que ocupen cargos de importancia en la estructura política local (al menos si se excluyen las escribanías), aunque en muchos casos resulta evidente su vinculación y relaciones con ella ${ }^{\text {I19. }}$.

Destaca asimismo el predominio de letrados: licenciados, bachilleres y escribanos se repiten de modo recurrente ${ }^{\mathrm{i} 20}$. Por norma general, el estudio del conjunto de la documentación concejil revela una relación inversa entre los negocios privados y la actividad puramente profesional: quienes aparecen con más recurrencia en la documentación oficial del concejo o recibiendo poderes de procuración de sujetos particulares no son acreedores encumbrados; en el extremo opuesto, el bachiller Ruy López Beato parece dedicarse con constancia y esmero sólo al otorgamiento de préstamos y a negocios conexos.

Se trata, por lo tanto, de un sector urbano diferente de la oligarquía que controla el gobierno de la villa en sentido estricto ${ }^{121}$. Sin embargo, su relevancia social es notoria, a causa en algunos casos de su formación profesional pero sobre todo por la presencia que le otorga su sólida posición económica. Sus bases materiales de reproducción son diversas, aunque principalmente están vinculadas a la captación del excedente campesino en la esfera de la circulación, en los intersticios del

116. Señala el predominio de prestamistas cristianos FurIó, «Endettement paysan», p. 142.

117. Debe tenerse presente que aquí solo figuran las operaciones a término, que requerían ser asentadas ante el notario, y no las compras o ventas pagadas en el acto.

118. González Jıménez, Manuel, «Cuaderno de notas de Gabriel Alfonso, escribano público de Carmona (14661468)», Historia. Instituciones. Documentos, 19 (1992), identifica también «una tupida red de intereses y personas unidas todas ellas por el afán de lucro» (p. 222).

119. Lo que se corresponde con la idea de una segmentación de la clase dominante urbana elaborada por JARA Fuente, Ob. cit. Véase también Idem, «Élites y grupos financieros en las ciudades castellanas de la Baja Edad Media», En la España medieval, 27 (2004), pp. 105-130.

120. Es una constatación habitual en las investigaciones; véase por ejemplo AsTARITA, Ob. cit., pp. 130-131.

121. Esto es, diferente de lo que JARA FUENTE, «Élites urbanas», denominaría como la «élite de poder», segmento superior de la clase dominante local; se trata de lo que este autor conceptualiza, adecuadamente, como una «élite de participación». 
aparato recaudatorio feudal o a través de la renta que devengan sus propiedades. Es notoria, en cambio, la falta de información sobre su vinculación a la esfera productiva; como hemos visto, con la excepción de Pedro de Peñafiel, no encontramos indicios de contratación de mano de obra que supere el uso doméstico ni de intervención en los mercados que permita suponer algo más que una mera especulación comercial. En cuanto a la actividad productiva agraria ocurre lo mismo: se caracterizan más por dar en arriendo tierras, animales e instrumentos de labranza a cambio de rentas que por gestionar ellos mismos el proceso de trabajo.

Esto también puede vincularse con un último fenómeno adicional, a saber: que las relaciones de endeudamiento aquí estudiadas no parecen dar lugar a una relación de subordinación económica cristalizada o sostenida en el tiempo. Esto es lo que se deriva del análisis de la situación de deudores que se ven obligados a tomar préstamos más de una vez en el lapso de tiempo analizado. A partir de sus nombres propios, del nombre de su padre y del lugar de vecindad, se puede identificar que io5 de los 670 deudores aparecen entre dos y cuatro veces en el registro de los 37 meses estudiados. Se trata de un número considerable de sujetos, si bien la mayoría no aparece más que una vez. Debe tenerse en cuenta, sin embargo, que el número de deudores reincidentes aumentaría si la serie disponible abarcara los meses siguientes a febrero de I45I, dado que la progresión del endeudamiento muestra una tendencia a profundizarse producto de la coyuntura agraria. Además, es imposible saber cuántos de los deudores que aquí aparecen una única vez también se endeudaron con prestamistas que consignaban sus operaciones con otros notarios, por lo que no tenemos registros de ellas.

Pero la mera identificación de los deudores reincidentes no da una imagen precisa de las relaciones que los ligan a los acreedores. Es más instructivo, para ello, observar no sólo quiénes se endeudan más de una vez, sino también quiénes lo hacen con el mismo prestamista. Esto constituye un indicio de la reproducción de una relación de subordinación económica continua en el tiempo entre dos sujetos determinados. El número de casos que entra en esta tipología es muy exiguo: apenas 28 deudores (un 4,2\% del total) se obligan más de una vez con el mismo prestamista. Es ciertamente inusual una situación como la de Juan Gutiérrez, tejedor, hijo de Juan Sánchez, vecino de Gotarrendura, endeudado cuatro veces con Pedro Suárez «el mozo» ${ }^{\mathrm{I} 2}$.

Dicho de otro modo, tres de cada cuatro deudores reincidentes distribuyen sus obligaciones entre dos o más acreedores. Por cierto, podría suponerse que esto obedece a la negativa de los prestamistas a renovar el crédito a un sujeto potencialmente insolvente. Sin embargo, de ser así esta política también debería excluir a quiénes ya están endeudados con otros acreedores, situación de la que el mismo notario guarda registro y que la relación existente entre los prestamistas

122. Catálogo, docs. 520, 8-4-1449; 550, 6-5-1449; 967, 2-4-1450; y 1617, 9-3-1451. 
más importantes hace dudar que estos no pudieran conocer. Sí podría ser, en cambio, una estrategia de los propios deudores para eludir una situación crónica de peligrosa dependencia personal respecto de un sólo acreedor. Sea como fuere, lo cierto es que la imagen que brinda la información sobre deudores reincidentes habla más de la eventual pauperización del común de los pecheros que de la consolidación de relaciones de dependencia económica respecto de un acreedor en particular.

Esto no significa, por supuesto, que no existieran vínculos más estables. El arrendamiento de tierras o animales de labor a cambio de parte del producto, fenómeno que aquí sólo hemos tratado de modo tangencial, es sin duda uno de ellos. Asimismo hemos visto algunos casos en que un acreedor realiza compras adelantadas a un sujeto que a su vez le debe dinero, lo que indica una relación de cierta recurrencia. Sin embargo, no son casos mayoritarios. La conclusión general que nos arriesgaríamos a esbozar es que la diversidad de fuentes de ingreso y de negocios lucrativos que caracteriza a estos sectores urbanos acaudalados es una estrategia que potencia su capacidad de captación del excedente campesino ${ }^{\mathrm{I2} 3}$. Sin embargo, ello a la vez obstaculiza tanto su conformación como clase definida por intereses que arraiguen en la esfera productiva, como también su capacidad para cristalizar relaciones de dependencia y subordinación estables respecto de otros sectores sociales. Dicho de otro modo, su fortaleza económica proviene de prácticas que también pueden explicar su debilidad para conformarse como sector social con perfil propio y con bases materiales diferenciadas ${ }^{124}$. En definitiva, esta suerte de clase «media» urbana de comerciantes y financistas, burguesa sólo en ese sentido, parece más un subproducto de la complejización propia de la sociedad feudal bajomedieval, antes que un emergente de relaciones sociales nuevas $^{125}$. Y sin embargo también puede decirse, por otro lado, que al apropiarse de una fracción del excedente de los productores por medio de los mecanismos analizados, se establece de hecho una potencial contradicción con las formas de explotación feudal que se nutren de la misma fuente. Tales hipótesis requieren, sin embargo, investigaciones de mayor alcance que la aquí presentada.

123. FURIÓ, «Endettement paysan».

124. Situación que tiene elementos en común con la analizada por DeL VAL VALDIVIESO, «Ascenso social», especialmente pp. 167-8.

125. FURIÓ, «Las élites rurales», p. 419, señala la imbricación entre élites y estructura feudal. 


\section{FUENTES Y BIBLIOGRAFÍA}

\subsection{FUENTES}

Barrios García, Ángel et al., Documentación del Archivo Municipal de Ávila (I256-I474), Ávila, Institución Gran Duque de Alba, I988.

Barrios García, Ángel; Luis Corral, Fernando; Riaño Pérez, Eugenio, Documentación medieval del Archivo Municipal de Mombeltrán, Ávila, Institución Gran Duque de Alba, 1996.

CabaÑas González, María Dolores, Documentación medieval abulense en el registro General del Sello, vol. XIII (I8-I-I497 a 22-XII-I497), Ávila, Institución Gran Duque de Alba, I996.

Cortes de los Antiguos Reinos de León y de Castilla, Real Academia de la Historia, Madrid, Tomos III-IV, I866-I882.

Del Ser Quijano, Gregorio, Documentación medieval abulense en el registro General del Sello, vol. XXII (I-V-I504 a 3I-XII-I504), Ávila, Institución Gran Duque de Alba, 2010.

-, Documentación medieval abulense en el Registro General del Sello, vol. IV (3I-VIII-I485 a 3-V-I488), Ávila, Institución Gran Duque de Alba, 1995.

-, Documentación medieval del Archivo Municipal de San Bartolomé de Pinares (Ávila), Ávila, Institución Gran Duque de Alba, 1987.

García Pérez, Juan, Documentación medieval abulense en el registro General del Sello, vol. XVIII (I-I-I502 a 30-X-I502), Ávila, Institución Gran Duque de Alba, 2007.

—, Documentación medieval abulense en el registro General del Sello, vol. XV (I8-I-I499 a 24XII-I499), Ávila, Institución Gran Duque de Alba, I996.

Hernández Pierna, Juan, Documentación medieval abulense en el registro General del Sello, vol. XI (3-I-I495 a I3-XII-I495), Ávila, Institución Gran Duque de Alba, I995.

Jiménez Hernández, Sonsoles y Redondo Pérez, Asunción, Catálogo de Protocolos Notariales del Archivo Histórico Provincial de Ávila (Siglo XV), dos tomos, Ávila, Institución Gran Duque de Alba, I992.

LAdERo Quesada, Manuel, Documentación medieval abulense en el registro General del Sello, vol. XX (22-V-I503 a 30-XI-I503), Ávila, Institución Gran Duque de Alba, 2007.

León Tello, Pilar, Judíos de Ávila, Ávila, Instituto «Gran Duque de Alba», I963 (Apéndice Documental).

Luis López, Carmelo, Documentación medieval abulense en el registro General del Sello, vol. XXI (I-X-I503 a 30-IV-I504), Ávila, Institución Gran Duque de Alba, 2007.

—, Documentación del Archivo Municipal de Ávila, vol. III (I478-I487), Ávila, Institución Gran Duque de Alba, I999.

-, Documentación medieval abulense en el registro General del Sello, vol. IX (30-VII-I493 a I7-IV-I494), Ávila, Institución Gran Duque de Alba, I996.

-, Documentación medieval abulense en el Registro General del Sello, vol. II (20-IX-I479 a I4-XII-I480), Ávila, Institución Gran Duque de Alba, I995.

Martín Rodríguez, José Luis, Documentación medieval abulense en el Registro General del Sello, vol. VIl (4-I-I492 a 24-XII-I492), Ávila, Institución Gran Duque de Alba, I996. 
-, Documentación medieval abulense en el Registro General del Sello, vol. I (30-X-I467 a I8IX-I479), Ávila, Institución Gran Duque de Alba, I995.

SAnz Fuentes, M. Josefa, Documentación medieval de la catedral de Ávila: Registro de Alfonso González de Bonilla (I7-VI-I465 a 5-VIII-I468), Ávila, Institución Gran Duque de Alba, 2014.

Sobrino Chomón, Tomás, Documentación del Archivo Municipal de Ávila. Vol. II (I436-I477), Ávila, Institución Gran Duque de Alba, I999.

—, Documentación medieval abulense en el Registro General del Sello, vol. III (I5-XII-I480 a I5-VIII-I485), Ávila, Institución Gran Duque de Alba, I993.

\subsection{BIBLIOGRAFÍA CITADA}

Aguilera BARChET, Bruno, «El préstamo en Extremadura a mediados del siglo XVI: notas para el estudio del derecho privado de la Corona de Castilla en la Edad Moderna», Anuario de la Facultad de Derecho, II (I993), pp. 299-320.

Álvarez-Carbajal, Francisco, El registro del notario Martín Fernández de Ruiforco (I468). Un escribano público en el Condado de Luna, Sevilla, Sociedad Española de Técnicas Historiográficas, 2014.

APARISI RoMERo, Fredric, «Las élites rurales en la Edad Media como objeto de estudio: de la marginalidad al centro del debate historiográfico», Historia. Instituciones. Documentos, 40 (20I3), pp. II-34.

Asenjo GonZÁlez, María, «Las ciudades medievales castellanas. Balance y perspectivas de su desarrollo historiográfico (I990-2004)», En la España medieval, 28 (2005), pp. 415-453.

-, «Labradores ricos: nacimiento de una oligarquía rural en la Segovia del siglo XV», En la España medieval, 4 (1984), pp. 63-86.

Astarita, Carlos, «Procuradores pecheros», en Idem, Del Feudalismo al capitalismo. Cambio social y político en Castilla y Europa Occidental, I250-I520, Valencia, PUV, 2005, Pp. II3-I44.

Benito Ruano, Eloy, «Usura y «cambios» en el León medieval», Archivos Leoneses, 47-48 (I970), pp. 203-208.

Bono y Huerta, José, «Conceptos fundamentales de la diplomática notarial», Historia. Instituciones. Documentos, I9 (1992), pp. 73-88.

Borrero Fernández, M. de las Mercedes, «Efectos del cambio económico en el ámbito rural. Los sistemas de crédito en el campo sevillano (fines del siglo XV y principios del XVI)», En la España medieval, 8 (1986), pp. 219-244.

Bourin, Monique, «Peasant Elites and Village Communities in the South of France, I200I350", Past and Present, I95 Suppl. 2 (2007), pp. IOI-II4.

Briggs, Chris, Credit and Village Society in Fourteenth Century England, Oxford, Oxford University Press, 2009.

BRITNELL, Richard, The Commercialization of English Society, IOoo-I500, Manchester, Manchester University Press, 1996.

BRUmont, Francis, Campos y campesinos de Castilla la Vieja en tiempos de Felipe II, Madrid, Siglo XXI, I984.

-, y CAmpbell, Bruce (eds.), A Commercialising Economy. England Io86 to c. I300, Manchester, Manchester University Press, I995.

Cantera Montenegro, Enrique, «La legislación general acerca de los judíos en el reinado de Juan II de Castilla», Espacio, Tiempo y Forma. Serie III. Historia Medieval, 25 (2012), pp. II9-I46. 
-, «Algunas notas sobre Abraham Bienveniste, Rab Mayor de los judíos y tesorero real en tiempos de Juan II de Castilla», Espacio, Tiempo y Forma. Serie III. Historia Medieval, 27 (2014), pp. I6I-I9I.

-, «Una familia de prestamistas y arrendadores judíos en tiempos de la expulsión: Los Soto de Aranda del Duero», Espacio, Tiempo y Forma. Serie III. Historia Medieval, I2 (I999), pp. II-46.

CASADO AlOnso, Hilario, Señores, mercaderes y campesinos. La comarca de Burgos a fines de la Edad Media, Valladolid, Junta de Castilla y León, I987.

CASAdo Quintanilla, Blas, «Nombramiento de escribanos públicos en Ávila, y sus circunstancias, en tiempos de los Reyes Católicos», Espacio, Tiempo y Forma, Serie III, Historia Medieval, I7 (2004), pp. II5-I30.

-, «Autenticidad documental y escribanos de Ávila en la Baja Edad Media», Espacio, Tiempo y Forma, Serie III, Historia Medieval, I (I988), pp. I75-I92.

CASTÁN LANASPA, Guillermo, «Créditos, deudas y pagos en el área rural castellano-leonesa (siglos XI-XIV)», Studia Historica. Hist. Medieval, I (I983), pp. 67-86.

CASTAÑo GonZÁLEZ, Javier, «Las aljamas judías de Castilla a mediados del siglo XV: la Carta Real de I450", En la España medieval, I8 (1995), pp. I8I-203.

Clavero, Bartolomé, Usura: del uso económico de la religión en la historia, Madrid, Tecnos, I984.

—, «Interesse: traducción e incidencia de un concepto en la Castilla del siglo XVI», Anuario de historia del derecho español, 49 (1979) pp. 39-98.

Clemente Ramos, Julián, «Élites rurales en Extremadura a finales de la Edad Media: el mayoral Juan Rubio (+I499)», Studia Historica. Historia Medieval, 29 (20II), pp. 229-246.

Соцомво, Octavio, «Por qué el campesino se endeuda? El significado de la usura medieval», Sociedades Precapitalistas. Revista de Historia Social, 5/I (2015), pp. I-20.

-, «La negociación en torno a la usura en Castilla, I258-I405. Economía, poder y religión en la Baja Edad Media», Anales de Historia Medieval, Universidad de Alicante, I4 (20032006), pp. 85-IIo.

Crespo Álvarez, Macarena, «Judíos, préstamos y usuras en la Castilla medieval. De Alfonso $\mathrm{X}$ a Enrique III», Edad Media. Revista de Historia, 5 (2002), pp. 179-215.

Da Graca, Laura, Poder político y dinámica feudal. Procesos de diferenciación social en distintas formas señoriales (siglos XIV-XV), Valladolid, Universidad de Valladolid, 2009.

Del VAl VAldivieso, M. Isabel, «Indicios de la existencia de una clase en formación: el ejemplo de Medina del Campo a fines del siglo XV», Anales de la Universidad de Alicante. Historia Medieval, 7 (1988-1989), pp. 193-224.

-, «Ascenso social y lucha por el poder en las ciudades castellanas del siglo XV», En la España Medieval, I7 (I994), pp. I57-I84.

Diago Hernando, Máximo, «El problema del aprovisionamiento de lana para la manufactura pañera castellana a fines de la Edad Media», Anuario de Estudios Medievales, 38/2 (2008), pp. 639-67I.

Diez Bedmar, M. del Consuelo, «Los libros de protocolos notariales del Archivo Histórico Provincial de Jaén», Boletín del Instituto de Estudios Giennenses, I83 (2003), pp. 69-I30.

Franco Silva, Alfonso, «Los señoríos de Oropesa y de Peñaranda de Bracamonte», en Del Ser Quijano, Gregorio (ed.), Historia de Ávila III. Edad Media (siglos XIV-XV), Ávila, Institución Gran Duque de Alba, 2006.

FurIó, Antoni, «Las élites rurales en la Europa medieval y moderna. Una aproximación de conjunto», en Rodríguez, Ana (ed.), El lugar del campesino. En torno a la obra de Reyna Pastor, Valencia, PUV, 2007, pp.39I-42I. 
—, «Endettement paysan et crédit dans la Péninsule Ibérique au Bas Moyen Âge», en BERTHE, Maurice (ed.), Endettement paysan et crédit rural dans l'Europe médiévale et moderne, Toulouse, Presses Universitaires du Mirail, I998, pp. 139-I67.

García de VALDEAVELlano, Luis, «El «Renovo»: notas y documentos sobre los préstamos usurarios en el reino astur-leonés (siglos X-XI)», Cuadernos de Historia de España, 57-58 (I973), pp. 408-448.

García Garcimartín, Hugo, Articulación jurisdiccional y dinámica socioeconómica de un espacio natural: la cuenca del Alberche (siglos XII-XV), Tesis Doctoral, Universidad Complutense de Madrid, 2002.

GonZÁlez JimÉnez, Manuel, «Cuaderno de notas de Gabriel Alfonso, escribano público de Carmona (I466-I468)», Historia. Instituciones. Documentos, I9 (I992), pp. 215-230.

Guerrero Navarrete, Yolanda, «Élites urbanas en el siglo XV: Burgos y Cuenca», Revista d' Historia Medieval, 9 (I998), pp. 8I-I04.

Hatcher, John, y Bailey, Mark, Modelling the Middle Ages. The History and Theory of England's Economic Development, Oxford, Oxford University Press, 200I.

Herrero JimÉnez, Mauricio, «Introducción», en Idem, Padrones y registros notariales abulenses en el Archivo de la Real Chancillería de Valladolid, Ávila, Institución Gran Duque de Alba, 20 Io.

JARA Fuente, José Antonio, «Élites y grupos financieros en las ciudades castellanas de la Baja Edad Media», En la España medieval, 27 (2004), pp. I05-130.

-, «Élites urbanas y sistemas concejiles: Una propuesta teórico-metodológica para el análisis de los subsistemas de poder en los concejos castellanos de la Baja Edad Media», Hispania, 207 (200I), pp. 22I-266.

KowALESki, Maryanne, Local Markets and Regional Trade in Medieval Exeter, Cambridge, Cambridge University Press, 2002.

LAdERo QUeSADA, Miguel Ángel, «I462: Un año en la vida de Enrique IV, rey de Castilla», En la España medieval, I4 (I99I), pp. 237-274.

—, La Hacienda Real de Castilla en el Siglo XV, Universidad de La Laguna, I973.

LE Goff, Jacques, La bolsa y la vida. Economía y religión en la Edad Media, Barcelona, Gedisa, 1987 .

LitTle, Lester, Pobreza voluntaria y economía de beneficio en la Europa medieval, Madrid, Taurus, I980.

LLIBRER ESCRIG, Josep, «Artesanos emprendedores en la industria textil. Del taller al mercado: El caso del pelaire contestano Bernat Martí (I469-I482)», En la España medieval, 37 (2014), pp. 295-3I7.

López FERnÁNDEZ, M. Isabel, La arquitectura del siglo XVI en Ávila: la casa de Bracamontey el patrimonio abulense, Tesis Doctoral, Universidad de Salamanca, $201 \mathrm{I}$.

Martínez Diez, Gonzalo, Las Comunidades de Villa y Tierra de la Extremadura castellana, Madrid, Ed. Nacional, I983.

Masschaele, James, Peasants, Merchants and Markets. Inland Trade in Medieval England, II5O-I350, New York, St. Martin's Press, I997.

MenAnt, François, y Jessenne, Jean- Pierre (eds.), Les Élites rurales dans l'Europe médiévale et moderne, Toulouse, Presses Universitaires du Mirail, 2007.

Monsalvo Antón, José María, Teoría y evolución de un conflicto social. El antisemitismo en la Corona de Castilla en la Baja Edad Media, Siglo XXI, Madrid, I985.

Moreno NúÑEz, José Ignacio, Ávila y su Tierra en la baja Edad Media (siglos XIII-XV), Ávila, Junta de Castilla y León, I992. 
Nelson, Benjamin, The Idea of Usury. From Tribal Brotherhood to Universal Otherhood, Chicago, University of Chicago Press, I969.

PADrós, Joan, «Endeudamiento y límites de la solidaridad campesina en la Cataluña del siglo XVI», Historia Agraria, 20 (2000), pp. 4I-60.

Rodríguez MAteos, Joaquín, «Escribanos públicos en Huelva: los protocolos notariales y el Archivo Histórico Provincial», Huelva en su historia, 8 (200I), pp. I3I-I50.

Rojas VACA, María Dolores, «Los inicios del notariado público en el reino de Castilla. Aportación a su estudio», Anuario de Estudios Medievales, 3I/I (200I), pp. 329-400.

SAlomon, Noël, La vida rural castellana en tiempos de Felipe II, Barcelona, Ariel, I982.

SALRACH, Josep, El hambre en el mundo. Pasado y presente, Valencia, PUV, 2012.

\subsection{APÉNDICE}

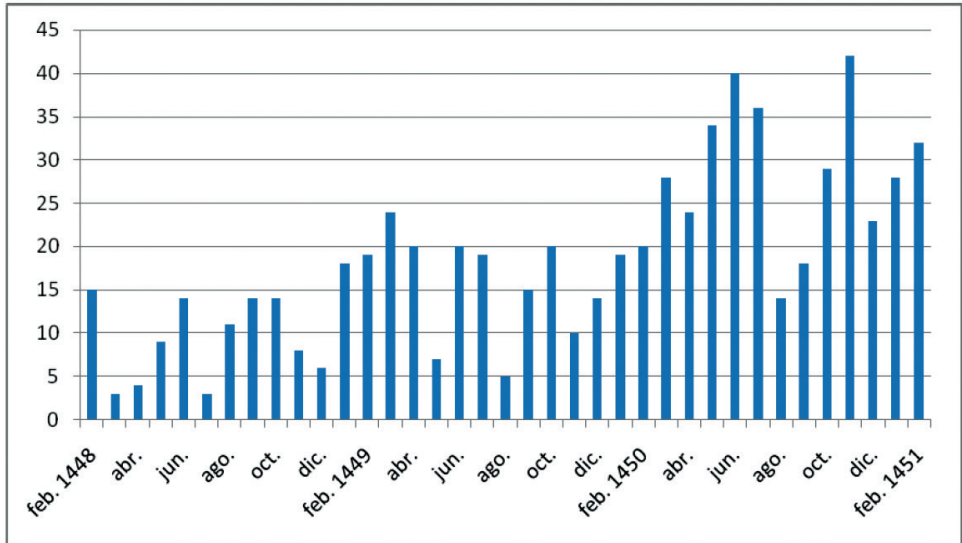

APÉNDICE 1: CANTIDAD DE PRÉSTAMOS POR MES, FEBRERO DE 1448 A FEBRERO DE 1451.

Fuente: elaboración propia en base a JimÉnEz Hernández, Sonsoles y Redondo PÉrez, Asunción, Catálogo de Protocolos Notariales del Archivo Histórico Provincial de Ávila (Siglo XV), dos tomos, Ávila, Institución Gran Duque de Alba, 1992. Del total de 705 casos, se excluyen 4 préstamos registrados entre el 26 y el 31 de enero de 1448, y 22 préstamos entre el 1 y el 13 de marzo de 1451, por tratarse de los meses incompletos al inicio y al final de la serie. 


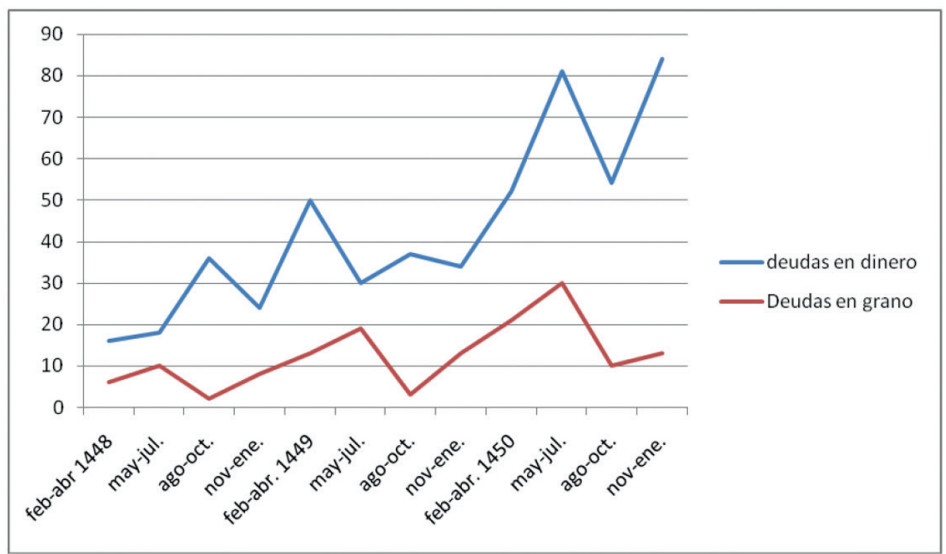

APÉNDICE 2: CANTIDAD DE PRÉSTAMOS EN DINERO Y DE PRÉSTAMOS EN GRANO POR TRIMESTRE.

Fuente: elaboración propia en base a JIMÉNEZ HERnÁNDEZ, Sonsoles y Redondo Pérez, Asunción, Catálogo de Protocolos Notariales del Archivo Histórico Provincial de Ávila (Siglo XV), dos tomos, Ávila, Institución Gran Duque de Alba, 1992. Se ordenan los trimestres a partir de febrero, de modo tal de iniciar el tercer trimestre con la cosecha de agosto.

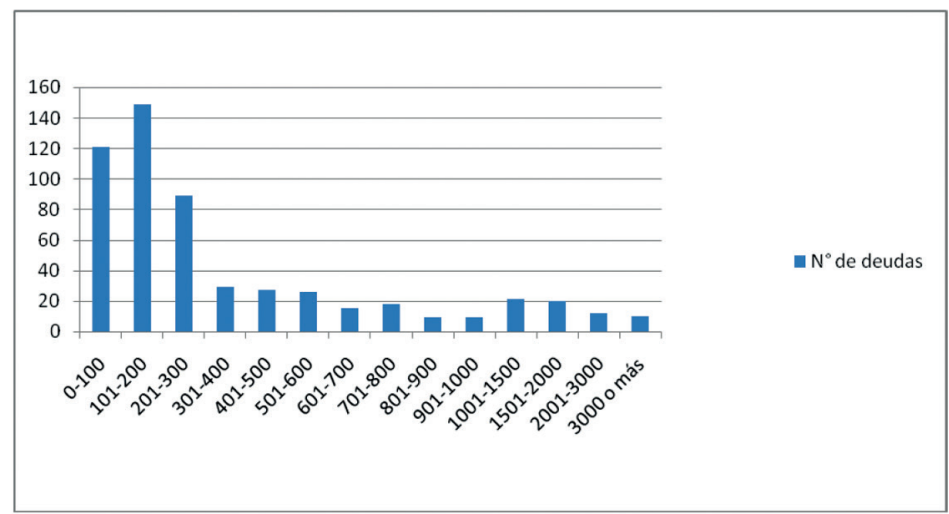

APÉNDICE 3: CANTIDAD DE PRÉSTAMOS SEGÚN SUS MONTOS EN MARAVEDÍES.

Fuente: elaboración propia en base a JimÉnEZ HERnÁNDEZ, Sonsoles y Redondo PÉrez, Asunción, Catálogo de Protocolos Notariales del Archivo Histórico Provincial de Ávila (Siglo XV), dos tomos, Ávila, Institución Gran Duque de Alba, 1992. Se incluyen un total de 555 préstamos consignados en maravedíes. Se excluyen por tanto las deudas en producto, para evitar cualquier distorsión que podría ocasionar una tasación incierta de los mismos; excluimos también 12 obligaciones consignadas en monedas áureas (doblas castellanas o florines de Aragón). 
Calidad de Revistas

científicas Españolas

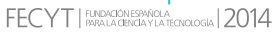

SERIE III HISTORIA MEDIEVAL

REVISTA DE LA FACULTAD DE GEOGRAFİA E HISTORIA
AÑO 2016

ISSN: 0214-9745

E-ISSN 2340-1362

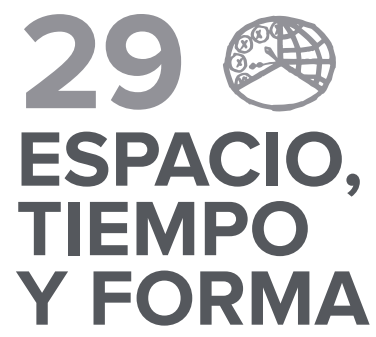

\section{Artículos}

17 Leticia Agúndez San Miguel

El tumbo de San Pedro de Montes como instrumento de recreación de la memoria instituciona

\section{Roberto Antuña Castro}

La copia de escrituras públicas a la muerte del notario titular

75 Carlos de Ayala Martínez

Alfonso VIII, Cruzada y Cristiandad

\section{Carlos Barquero Goñ I}

La renta señorial de la Orden de San Juan en Castilla durante los siglos XII y XIII

\section{MARgARITA CABRERA SÁNCHEZ}

Cristianos nuevos y cargos concejiles. Jurados conversos en Córdoba a fines del Medievo

183 Francisco de Paula Cañas Gálvez

La correspondencia de Leonor de Alburquerque con su hijo Alfonso $V$ de Aragón: acción política y confidencia familiar del partido aragonés en la corte de Castilla (1417-1419)

\subsection{Octavio Colombo} del siglo XV

os dueños del dinero. Prestamistas abulenses a mediados

\section{Alfonso Domínguez de LA CONCHA \\ Apropiaciones de comunales en la Puebla de Guadalupe} (Cáceres) durante la Baja Edad Media

\section{Antonio Vicente Frey SÁnChez}

Sobre la articulación administrativa de la cuenca del río Segura entre los siglos VII y VIII: algunos recientes elementos para identificar una frontera «blanda»

\section{David Gallego VALLE}

La fortificación medieval en el Campo de Montiel (ss. VIII-XVI). Análisis de su secuencia histórica y constructiva

\section{MAURICIO HERRERO JIMÉNEZ}

El cuidado del alma y otros cuidados en las cartas de aniversario del cabildo de los clérigos de Cuéllar en el siglo XIV
4.01 JaIME DE HOZ OnRUBIA

Antroponimia y reconstrucción histórica: consideraciones sobre la identificación personal en el paso de la Edad Media a la Moderna en la Corona de Castilla

\section{Carmen López Martínez \\ Sancho IV de Castilla y la imposición del diezmo mudéjar} en Murcia

\subsection{PABlo Martín Prieto} el valor de los preámbulos

Idea e imagen del rey en la diplomática medieval hispana:

\section{Luis Martínez García}

Los campesinos al servicio del señor, según los fueros locales burgaleses de los siglos XI-XIII

54.3 Juan José Morales Gómez

Las minas de alumbre del bajo jiloca (Zaragoza) y su explotación a fines de la Edad Media

571 DAVID D. NAVARRO

Precisiones literarias sobre el antijudaísmo de Gonzalo de Berceo en el Milagro de Teófilo (XXIV)

593 JaIME PIQUeras JuAN

Matrimonios en régimen de germania y relaciones intrafamiliares en Alicante durante el siglo XV

621 Aída PORTILLA GonzÁlez

El arte del buen morir en los testamentos medievales de la catedral de Sigüenza (siglos XIII-XV)

675 María Del Pilar RÁbade Obradó

Justas, fiestas y protagonismos: Alegrías y placeres en El Victorial de Gutierre Díaz de Games

699 TERESA SÁnchez ColladA

La dote matrimonial en el Derecho castellano de la Baja Edad Media. Los protocolos notariales del Archivo Histórico Provincial de Cuenca (1504-1507)

\section{Casto Manuel Solera Campos}

Pureza y continencia durante la Edad Media: la castidad conyugal en la Orden de Santiago (siglos XII-XVI)

\section{7 ÓsCAR VILLARROEL GONZÁlEZ}

Autoridad, legitimidad y honor en la diplomacia: los conflictos anglo-castellanos en los concilios del siglo XV

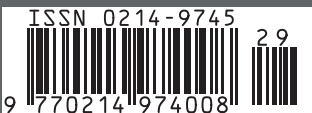




\section{9}

\section{ESPACIO,}

\section{TIEMPO}

Y FORMA

UกED

SERIE III HISTORIA MEDIEVAL

REVISTA DE LA FACULTAD DE GEOGRAFİA E HISTORIA

\section{Libros}

817 Álvarez Fernández, María y Beltrán SuÁrez, Soledad, Vivienda, gestión y mercado inmobiliarios en Oviedo en el tránsito de la Edad Media a la modernidad. El patrimonio urbano del cabildo catedralicio (RobERTO J. GONZÁlez ZALACAín)

821 BeCEIro PITA, Isabel (dir.), Poder, piedad y devoción. Castilla y su entorno, siglos XII-XV (ANA ECheVARría ARSUAGA)

825 García Fernández, Ernesto (Coord.), Laguardia y sus fueros. Estudios Históricos realizados en conmemoración del 850 aniversario de la concesión de la carta fundacional (ANA MARÍA RIVERA MEDINA)

829 García Fernández, Ernesto y Bonachía Hernando, Juan Antonio (eds.), Hacienda, mercado y poder al Norte de la Corona de Castilla en el tránsito del Medievo a la Modernidad (AnA María Rivera Medina)

843 Martín Prieto, Pablo, Las matemáticas en la Edad Media: una historia de las matemáticas en la Edad Media occidental (ANTONIO HERNANDO Esteban)

847 Miranda García, Fermín, Breve Historia de los Godos (Ana María JIMÉNEZ GARNICA)

851 Moreno Ollero, Antonio, Los dominios señoriales de la Casa de Velasco en la Baja Edad Media (DIEGo ARSUAGA LABORDE)

855 ORTEgo Rico, Pablo, Poder financiero y gestión tributaria en Castilla: Los agentes fiscales en Toledo y su reino (1429-1504) (Ana María Rivera Medina)

861 Solórzano Telechea, Jesús A. \& Arízaga bolumburu, Beatriz \& AgUiAR ANDRADE, Amélia (editores), Ser mujer en la ciudad medieval eUrOPEa (MARIANA ZAPATERO)

869 Solórzano Telechea, Jesús A. \& Arízaga bolumburu, Beatriz \& Sicking, Louis (eds.), Diplomacia y comercio en la Europa Atlántica Medieval (Roberto J. GonzÁlez ZaLACAín)

875 VÍtORES CASADO, Imanol \& GoICOLEA JULIÁN, Francisco Javier \& ANGULO Morales, Alberto \& Aragón RuAno, Álvaro (edición y estudios), Hacienda, fiscalidad y agentes económicos en la Cornisa Cantábrica y su entorno (1450-1550). Nuevos textos para su estudio (ENRIQUE CANTERA MONTENEGRO) 